\title{
A taxonomic revision of the south-eastern dragon lizards of the Smaug warreni (Boulenger) species complex in southern Africa, with the description of a new species (Squamata: Cordylidae)
}

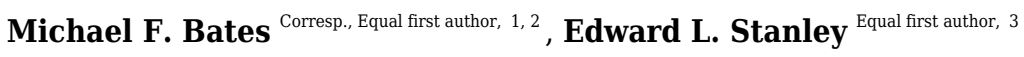 \\ ${ }^{1}$ Department of Herpetology, National Museum, Bloemfontein, South Africa \\ 2 Department of Zoology and Entomology, University of the Free State, Bloemfontein, South Africa \\ 3 Department of Herpetology, Florida Museum of Natural History, Gainesville, Florida, United States \\ Corresponding Author: Michael F. Bates \\ Email address: herp@nasmus.co.za
}

A recent multilocus molecular phylogeny of the large dragon lizards of the genus Smaug Stanley et al., 2011 recovered a south-eastern clade of two relatively lightly-armoured, geographically-proximate species (S. warreni [Boulenger, 1908] and S. barbertonensis [Van Dam, 1921]) here referred to as the $S$. warreni species complex. Unexpectedly, $S$. barbertonensis was found to be paraphyletic, with individuals sampled from northern Eswatini (formerly Swaziland) being more closely related to $S$. warreni than to $S$. barbertonensis from the type locality of Barberton in Mpumalanga Province, South Africa. Examination of voucher specimens used for the molecular analysis, as well as most other available museum material of the three lineages, indicated that the 'Eswatini' lineage-including populations in a small area on the northern Eswatini-Mpumalanga border, and northern KwaZulu-Natal Province in South Africa-was readily distinguishable from S. barbertonensis sensu stricto (and S. warreni) by its unique dorsal, lateral and ventral colour patterns. In order to further assess the taxonomic status of the three populations, a detailed morphological analysis was conducted. Multivariate analyses of scale counts and body dimensions indicated that the 'Eswatini' lineage and S. warreni were most similar. In particular, S. barbertonensis differed from the other two lineages by its generally lower numbers of transverse rows of dorsal scales, and a relatively wider head. High resolution Computed Tomography also revealed differences in cranial osteology between specimens from the three lineages. The 'Eswatini' lineage is described here as a new species, Smaug swazicus sp. nov., representing the ninth known species of dragon lizard. The new species appears to be near-endemic to Eswatini, with about $90 \%$ of its range located there. Our study indicates that $S$. barbertonensis sensu stricto is therefore $a$ South African endemic restricted to an altitudinal band of about $300 \mathrm{~m}$ in the 
Barberton-Nelspruit-Khandizwe area of eastern Mpumalanga Province, while S. warreni is endemic to the narrow Lebombo Mountain range of South Africa, Eswatini and Mozambique. We present a detailed distribution map for the three species of the $S$. warreni species complex, and a revised diagnostic key to the genus Smaug. 
2 A taxonomic revision of the south-eastern dragon lizards of the Smaug warreni

3 (Boulenger) species complex in southern Africa, with the description of a new

4 species (Squamata: Cordylidae)

7 Michael F. Bates ${ }^{1,2}$, Edward L. Stanley ${ }^{3}$

8

$9 \quad{ }^{1}$ Department of Herpetology, National Museum, P.O. Box 266, Bloemfontein 9300, Free State 10 Province, South Africa

11 2Department of Zoology and Entomology, University of the Free State, P.O. Box 339,

12 Bloemfontein 9300, Free State Province, South Africa

13 '3 Department of Herpetology, Florida Museum of Natural History, Gainesville, Florida, 32611, 14 USA

15

16 Corresponding author:

17 Michael F. Bates

1836 Aliwal Street, Bloemfontein, South Africa

19 herp@nasmus.co.za 


\section{ABSTRACT}

22 A recent multilocus molecular phylogeny of the large dragon lizards of the genus Smaug Stanley

23 et al., 2011 recovered a south-eastern clade of two relatively lightly-armoured, geographically24 proximate species (S. warreni [Boulenger, 1908] and S. barbertonensis [Van Dam, 1921]) here 25 referred to as the $S$. warreni species complex. Unexpectedly, S. barbertonensis was found to be 26 paraphyletic, with individuals sampled from northern Eswatini (formerly Swaziland) being more 27 closely related to $S$. warreni than to $S$. barbertonensis from the type locality of Barberton in 28 Mpumalanga Province, South Africa. Examination of voucher specimens used for the molecular analysis, as well as most other available museum material of the three lineages, indicated that the 'Eswatini' lineage - including populations in a small area on the northern Eswatini-Mpumalanga border, and northern KwaZulu-Natal Province in South Africa - was readily distinguishable from S. barbertonensis sensu stricto (and S. warreni) by its unique dorsal, lateral and ventral colour patterns. In order to further assess the taxonomic status of the three populations, a detailed morphological analysis was conducted. Multivariate analyses of scale counts and body dimensions indicated that the 'Eswatini' lineage and S. warreni were most similar. In particular, S. barbertonensis differed from the other two lineages by its generally lower numbers of transverse rows of dorsal scales, and a relatively wider head. High resolution Computed Tomography also revealed differences in cranial osteology between specimens from the three lineages. The 'Eswatini' lineage is described here as a new species, Smaug swazicus sp. nov., representing the ninth known species of dragon lizard. The new species appears to be nearendemic to Eswatini, with about $90 \%$ of its range located there. Our study indicates that $S$. barbertonensis sensu stricto is therefore a South African endemic restricted to an altitudinal band of about $300 \mathrm{~m}$ in the Barberton-Nelspruit-Khandizwe area of eastern Mpumalanga Province, while $S$. warreni is endemic to the narrow Lebombo Mountain range of South Africa, Eswatini and Mozambique. We present a detailed distribution map for the three species of the $S$. warreni species complex, and a revised diagnostic key to the genus Smaug. 


\section{INTRODUCTION}

50 The Cordylidae consists of two subfamilies, Cordylinae (nine genera, 52 species) and

51 Platysaurinae (one genus, 16 species), and is the only lizard family endemic to the mainland of

52 Africa (Stanley et al., 2011; Bates et al., 2014; Reissig, 2014; Whiting et al., 2015; Stanley et al.,

53 2016; Marques et al., 2016; Uetz et al., 2019). Until recently, only four genera (Cordylus

54 Laurenti, 1768, Chamaesaura Schneider, 1801, Pseudocordylus A. Smith, 1838, Platysaurus A.

55 Smith, 1844) were recognised in the family, but Stanley et al. (2011) erected five new genera

56 (Smaug, Ninurta, Ouroborus, Karusasaura, Namazonurus) and resurrected Hemicordylus A.

57 Smith, 1838. The genus Smaug consists of eight species, of which the large and only terrestrial

58 form, S. giganteus (A. Smith, 1844), is genetically highly divergent (Stanley et al., 2011; Stanley

$59 \&$ Bates, 2014). The other seven species had been treated as the 'Cordylus warreni' (Boulenger,

60 1908) species complex (e.g Branch, 1988; Jacobsen, 1989).

61

62

63

64

65

66

67

68

69

70

71

72

73

Members of the 'Cordylus warreni' species complex (S. warreni, S. barbertonensis [Van Dam, 1921], S. depressus [FitzSimons, 1930], S. breyeri [Van Dam, 1921], S. vandami

[FitzSimons, 1930], S. mossambicus [FitzSimons, 1958] and S. regius [Broadley, 1962]) are

5 large, robust and spinose girdled lizards (family Cordylidae) restricted to high-elevation regions

6 of the north-eastern provinces of South Africa and Eswatini (also spelled 'eSwatini', formerly

7 Swaziland), and the highlands of eastern Zimbabwe and adjacent Mozambique. Like most

girdled lizards, members of the $S$. warreni complex are strictly rupicolous, inhabiting deep,

9 horizontal or gently sloping crevices, often in shaded rocky outcrops (Jacobsen, 1989; Stanley \&

Bates, 2014). Due to their reliance on deep crevices they appear to be relatively substrate-

1 specific, occurring in partially-vegetated boulder fields on gentle slopes.

The seven currently recognised taxa in the $S$. warreni complex (as defined above) are 74 allopatric, occurring on separate mountain chains, and are distinguishable on the basis of 75 differences in scalation and colour pattern (Jacobsen, 1989; Branch, 1998; Bates et al., 2014;

76 Stanley \& Bates, 2014). Despite these clear diagnoses, the $S$. warreni group has a tortuous 77 taxonomic history (see Stanley \& Bates, 2014). For example, FitzSimons (1943) treated Cordylus 78 barbertonensis, C. b. depressus and C. breyeri as subspecies of $C$. warreni, retained the 79 subspecies C. vandami perkoensis (FitzSimons, 1930), and continued to recognise C. laevigatus 
80 (FitzSimons, 1933) as a valid species. Shortly thereafter, Loveridge (1944) revised the

81 Cordylidae and treated all seven of the above taxa as subspecies of Cordylus warreni. FitzSimons

82

83

84

85

86

87

88

89

90

91

92

93

94

95

96

97

98 (1958) later described Cordylus warreni mossambicus, and Broadley (1962) described C. warreni regius. Cordylus warreni was therefore considered a polytypic species with as many as nine subspecies (Branch, 1988). Jacobsen (1989) subsequently investigated the status of South African populations and on the basis of sympatry between C.w. vandami and C. w. breyeri at one locality, he recognised vandami as a full species. As a result of overlapping morphological character variation (scalation and colour pattern) he considered C. w. perkoensis a junior synonym of $C$. vandami, and $C$. w. laevigatus a junior synonym of $C$. w. depressus. Branch (1998) later followed Jacobsen's (1989) arrangement for South African and Eswatini taxa, but also treated $C$. breyeri, $C$. w. mossambicus and $C$. w. regius as valid species (without providing reasons). Broadley (2006) treated all seven taxa in the $C$. warreni complex (except laevigatus and perkoensis) as full species, but he too failed to provide justification for such action.

In a recent multilocus molecular study using three mitochondrial and three nuclear genes, Stanley et al. (2011) recovered the genus Cordylus as paraphyletic and allocated all members of the $C$. warreni complex, together with the large terrestrial species $C$. giganteus Smith, 1844, to a new genus, Smaug. A subsequent multilocus molecular phylogeny-using three mitochondrial and eight nuclear genes - that focused on the S. warreni complex found that S. warreni, $S$. barbertonensis, $S$. depressus, S. breyeri, S. vandami, S. mossambicus and S. regius are all valid species (Stanley \& Bates, 2014) (Fig. 1). The authors identified a south-eastern clade of three species-level taxa (hereafter referred to as the $S$. warreni species complex), comprising $S$. warreni and two lineages of $S$. barbertonensis from northern Eswatini and Mpumalanga Province, South Africa. The latter taxon was shown to be paraphyletic, with samples from northern Eswatini being more closely related to $S$. warreni than to topotypic S. barbertonensis, and with genetic distances between the three lineages of $6-10 \%$ for the mitochondrial marker ND2. This led us to hypothesise that diagnosable morphological differences should exist between specimens referable to the three lineages.

FitzSimons (1943: 427) had in fact noted regional differences in colouration in specimens of Cordylus warreni barbertonensis as follows: "sides of body and tail with vertical barring of 
111 yellow", "Lower surfaces brown, with irregularly scattered yellowish spots or short transverse 112 bars" (Barberton, South Africa) versus "sides of body and tail with series of large yellow spots 113 and narrow dark interspaces", "lower surfaces yellowish-white, with irregular dark brown

114 transverse bars on chest and belly, chin spotted with blackish and throat with vermiculate 115 blackish markings" (Eswatini), but he did not suspect that this indicated separate taxonomic 116 status for the two colour forms. Jacobsen (1989) examined 24 specimens of C. $w$. barbertonensis 117 from Mpumalanga and the adjacent northern part of KwaZulu-Natal (formerly part of 118 Transvaal), but did not distinguish different colour patterns.

119

120

In the present study it was found that specimens of the two 'S. barbertonensis' lineages 121 had consistently different dorsal, lateral and ventral colour patterns, as well as other morphological differences. Populations from Eswatini and adjacent areas in Mpumalanga and 123 KwaZulu-Natal provinces in South Africa, initially referred to as 'Smaug cf. barbertonensis' in this paper, are therefore described here as a new species.

125

126

MATERIALS AND METHODS

\section{Study area}

128 The study area comprises the South African provinces of Mpumalanga and (northern) KwaZulu129 Natal, as well as Eswatini and adjacent parts of southern Mozambique. This area is bounded by 130 latitudes $25^{\circ} \mathrm{S}$ and $28^{\circ} \mathrm{S}$, and longitudes $30^{\circ} 30^{\prime} \mathrm{E}$ and $32^{\circ} 30^{\prime} \mathrm{E}$.

\section{Material examined}

All available specimens in the Ditsong National Museum of Natural History, Pretoria (TM) and National Museum, Bloemfontein (NMB) were examined by MFB. Material of Smaug collected during Jacobsen's (1989) survey of the former Transvaal Province and Boycott's (1992) survey of Eswatini was, for the most part, deposited at Ditsong, and this includes the vast majority of museum material identified as $S$. warreni and $S$. barbertonensis. Some non-types of the new species referred to below are housed at the American Museum of Natural History, New York (AMNH), Durban Natural Science Museum, Durban (DNSM), and Natural History Museum of 
140 Zimbabwe, Bulawayo (NMZB); and a few specimens of $S$. warreni are in the collections of 141 AMNH and NMZB.

142 and/or altitudes ( $\mathrm{m}$ above sea level) were not available in museum documentation, these were estimated using Google Earth Pro.

146

In addition to the data presented in this paper, comparative data consulted for the diagnoses of species and for the purposes of preparing a diagnostic key (see below) were obtained from 149 specimens listed in Table S2 and Boulenger (1908), Van Dam (1921), FitzSimons (1930, 1933, 1943, 1958), Loveridge (1944), Broadley (1962, 1966), De Waal (1978), Jacobsen (1989), Stanley et al. (2011) and Mouton et al. (2018).

152

153

154

155

156

157

158

159

160

161

162

163

164

165

166

167

168

169

170

When collection co-ordinates (presented as degrees, minutes, and in many cases seconds) Stanleyetal. (2011) and Mouronetal. (2018).

\section{Ethics approval}

This project was approved by the National Museum Bloemfontein Ethics Clearance Committee (NMB ECC 2019/13).

\section{External morphology}

Measurements: Snout to vent length (SVL) was measured from the tip of the snout to the vent after flattening the specimen on its back. Tail length, from vent to tip of tail._Head measurements (determined using vernier callipers and, unless otherwise stated, taken on the right side unless damaged): Length, measured from tip of snout to ear opening; width, at widest point at about the level of the posterior borders of the parietals; depth, from middle of posterior sublabial to highest point of posterior parietal. Scalation (examined by MFB using a binocular dissecting microscope, mostly a Nikon SMZ 745T): For the most part the morphological characters employed by FitzSimons (1943) were used, and in the same way, unless otherwise indicated. To avoid uncertainty, the following scale counts are described in detail: occipitals: large scales behind the posterior parietals, the outermost ones situated directly behind the elongated upper temporals; gular scales (often elongated and in longitudinal rows): counted transversely between posterior sublabials, the first row extending to the anterior end of the posterior sublabial; dorsal scale rows longitudinally: counted across the widest part of the body more-or-less midway between fore- 
171 and hindlimbs (scales of the most lateral rows are at least half the width of adjacent enlarged

172 dorsals); dorsal scale rows transversely: counted from the first complete row behind the

173 occipitals to the row that ends immediately anterior to the vent (when followed around to the

174 ventral side); ventral scale rows longitudinally: counted across the widest part of the body, more-

175 or-less midway between fore- and hindlimbs (lateral ventrals are rectangular or quadrangular,

176 smooth or weakly keeled, flattened, and at least half the size of adjacent ventrals); ventral scale

177 rows transversely: counted from the first row (which curves anteriorly) behind the posterior part

178 of the forelimb insertion to the row (which curves posteriorly) immediately in front of the

179 anterior part of the hindlimb insertion (i.e. scale rows between axilla and groin); lamellae under

1804 th toe of right foot were counted from the first scale entirely or largely [>60\%] anterior to the

181 junction between 3rd and 4th toes to the scale behind the claw, and incomplete lamellae (i.e.

182 those that do not extend to either side) were excluded. Sexing: Males (>70 mm SVL) were

183 identified by the presence of large femoral pores (usually with waxy plugs of secreted fluid) as

184 well as differentiated femoral scales (generation glands). Females ( $>70 \mathrm{~mm} \mathrm{SVL}$ ) had minute

185 pin-prick-like femoral pores without waxy plugs, and lacked differentiated femoral scales.

186

187 Osteological data

188 Osteological data was obtained from representative specimens of the $S$. warreni species complex 189 via High Resolution X-ray Computed Tomography (HRCT). Specimens used were: S. warreni 190 NMB R9292, AMNH-R-173381; S. barbertonensis NMB R9196 (topotype); S. cf.

191 barbertonensis NMB R9201 (holotype of new species, see below), AMNH-R-173382. These

192 specimens were scanned using a Phoenix v|tome|x S CT scanner at the American Museum of

193 Natural History's Microscopy and Imaging Facility, and GE Inspection Technologies, LP

194 Technical Solutions Center in San Carlos, California, or on a Phoenix v|tome|x M at the

195 University of Florida's Nanoscale Research Facility. Each specimen was scanned twice: once to

196 recover the full body, and a second higher resolution scan to focus on the cranial morphology.

197 Current, voltage, and detector-time were modified to optimise the grayscale range, and

198 specimens were scanned in sections to maximise resolution (Table S1). Raw data were processed

199 using GE's proprietary datos|x software V.2.3 to produce a series of tomogram images which

200 were then viewed, sectioned, measured and analysed using VG Studio Max 2.2 (Volume

201 Graphics, Heidelberg, Germany). Individual skeletal elements and osteoderms were 
202 reconstructed separately for each scan, so as to facilitate osteological analysis. Tomograms and 203 3D mesh files for all datasets are available online at www.morphosource.org (see supplementary 204 data for DOIs).

205

\section{Statistical analyses}

207 Univariate analyses of scale counts was conducted using Statistica v. 6. Principal component and 208 linear discriminant analyses were run for three mensural characters (head length, width and 209 height) and 13 meristic characters (supraciliaries, suboculars, supralabials, infralabials, 210 sublabials, occipitals, gulars, dorsal scale rows transversely and longitudinally, ventral scale 211 rows transversely and longitudinally, femoral pores, subdigital lamellae on fourth toe), taken 212 from 72 museum specimens (>70 mm SVL; i.e. juveniles excluded to avoid the effects of 213 ontogenetic growth) (Table S2), using the prcomp and lda commands in R \{stats $\}$ and $\{$ MASS . 214 When scale counts were made on both sides of the head or on both hindlimbs (see Table S2), a 215 mean value was used for the analyses.

216

\section{Species concept and species delimitation}

218 We apply a lineage-based species concept whereby a species is represented by an independently 219 evolving metapopulation lineage (see Frost \& Hillis, 1990; De Queiroz, 1998, 2007). The 220 genetic distinctness described by Stanley \& Bates (2014) and morphological characters were the 221 operational criteria for species delimitation. Although Stanley \& Bates (2014) did not employ 222 coalescent species delimitation analyses, the topological consistency of the mtDNA, nuDNA and 223 combined analyses strongly support the existence of three distinct lineages within $S$. warreni and 224 S. barbertonensis.

225

\section{Nomenclatural note}

227 The electronic version of this article in Portable Document Format (PDF) will represent a 228 published work according to the International Commission on Zoological Nomenclature (ICZN), 229 and hence the new names contained in the electronic version are effectively published under that 230 Code from the electronic edition alone. This published work and the nomenclatural acts it 231 contains have been registered in ZooBank, the online registration system for the ICZN. The 
232 ZooBank LSIDs (Life Science Identifiers) can be resolved and the associated information viewed 233 through any standard web browser by appending the LSID to the prefix http://zoobank.org/. The 234 LSID for this publication is: [urn:lsid:zoobank.org:pub:490BDD66-155F-423F-A4E9-

235 DEAEEB024CC5]. The online version of this work is archived and available from the following 236 digital repositories: PeerJ, PubMed Central and CLOCKSS.

\section{RESULTS}

\section{Character analysis}

240 Dorsal colour pattern. (Fig. 2) Specimens from all three clades recovered by Stanley \& Bates 241 (2014) are distinguishable on the basis of dorsal, lateral and ventral colour patterns. Smaug 242 warreni has a medium to sandy brown (sometimes reddish-brown) dorsum with a series of 5-6 243 interrupted transverse bands between fore- and hindlimbs, each consisting of white or cream 244 ocelli (spots or blotches) with dark (often black) borders. The dark-edges exaggerate the ocelli, 245 but some specimens have only small pale markings which also lack heavy dark borders. The 246 dorsum of $S$. barbertonensis is medium to dark brown (or even black), usually with 4-5

247 interrupted bands on the back formed mostly by transversely enlarged pale markings (rather than 248 spots or blotches) with moderately dark edges. Smaug cf. barbertonensis is similar to the latter 249 form, but there are usually 5-6 bands. However, in S. barbertonensis there is almost always a 250 pale spot on the nape immediately posterior to the median occipitals, followed in close proximity 251 by a distinct transverse band. In $S$. cf. barbertonensis, the spot on the nape is replaced by a pale 252 band, followed after a distinct gap by another pale band (often divided medially) on the neck 253 with a slightly posteriorly-directed curvature. Smang warreni also has a pale band behind the 254 occipitals, but the band that follows is seldom curved as in the case of the previous form.

255

Ventral colour pattern. (Fig. 2) In S. warreni the belly is generally white with the centre of each 257 scale pale brown; the throat is usually mostly white with scattered small to medium-sized dark

258 brown spots. In $S$. barbertonensis the belly is almost completely black or dark brown, with only 259 a few pale markings on the sides; the throat is also almost entirely dark, with only occasional 260 pale specks or blotches. In $S$. cf. barbertonensis the belly is white with 5-6 broad, dark brown 261 'cross-bands', interrupted mid-ventrally by six longitudinal rows of brown scales; the throat is 
262 white with bold, dark mottling or reticulations (sometimes forming transverse bands; most of the 263 throat is dark).

264

265 Lateral colour pattern. (see below) The flanks of $S$. warreni are often mostly cream with a few 266 dark markings, but may consist of alternating light and dark vertical bands. In S. barbertonensis 267 the flanks are primarily dark brown or even black, with a few narrow or moderate cream bands 268 and/or spots/blotches. In contrast, the sides of the body in S. cf. barbertonensis consist of large 269 cream spots or blotches on a dark background. In some cases the light patch behind the armpit is 270 elongated (antero-posteriorly).

271

272 Scales at the edges of the ear openings. Smaug barbertonensis usually has generally elongated 273 and spinose scales at the anterior edges of the ear openings (especially the central ones), whereas 274 in most cases these scales are short and non-spinose in $S$. cf. barbertonensis and S. warreni. 275

276 Relative length of occipital scales. In all three forms in the complex there are usually six 277 occipital scales, and the scales of the median pair are shorter and usually smaller than the others 278 (although usually less distinctly so in $S$. warreni). In $S$. warreni the outer occipital is usually of 279 similar size and shape to the adjacent inner occipital, but in $S$. barbertonensis and $S$. cf. 280 barbertonensis the outer one is usually shorter and smaller. In S. warreni a small median 281 occipital is common.

282

283 Quadrate variation. In S. cf. barbertonensis the quadrates have a pronounced ridge and concave 284 region at the lateral edge of the adductor musculus mandibulae posterior origin, whereas in $S$. 285 barbertonensis and S. warreni the quadrates have a less pronounced ridge and a non-concave 286 region (Fig. 3).

287

288 Scale counts. The three forms are similar in terms of scale counts (Table 1), but $S$.

289 barbertonensis usually has lower numbers of transverse dorsal scale rows than $S$. warreni and $S$. 290 cf. barbertonensis (28-34 versus 31-41; Fig. 4A). 
292 Head width. Smaug barbertonensis, when compared to both S. warreni and S. cf. barbertonensis, 293 usually has a wider head relative to snout-vent length (SVL) (Fig. 4B).

294

295 Spinosity. A recent study by Mouton et al. (2018) that investigated the relationship between 296 generation gland morphology and armour in the genus Smaug found that those species with 297 multi-layer generation glands (S. giganteus, S. breyeri, S. vandami) had relatively long (basal) 298 tail and occipital spines, while all other species (including S. warreni, S. barbertonensis and $S$. 299 cf. barbertonensis) had two-layer glands and relatively short spines. The latter two forms were 300 found to be more spinose than $S$. warreni (i.e. longer occipital scales and proximal caudal 301 spines).

302

303 Statistical analyses

304 Both principal components and linear discriminant analyses reveal clear separation in scale 305 characters between $S$. warreni and S. barbertonensis, and S. cf. barbertonensis and $S$.

306 barbertonensis (4\% LDA mis-classification rate in both cases) (Fig. 4C-D, Tables S3-4). Smaug 307 cf. barbertonensis and S. warreni display similar pholidosis and head proportions and cannot be 308 consistently sorted by these characters alone (25\% LDA mis-classification rate). The first two 309 principal components explain $32 \%$ of the variation in the dataset.

310

311 Systematics

312 Family Cordylidae Gray, 1838

313 Smaug swazicus Bates \& Stanley sp. nov.

314 Swazi Dragon Lizard

315 Figs 5-8, Tables 2-3

316 urn:Isid:zoobank.org:act:A942675E-5E76-4FC9-AA8F-BFA7A4C131C7

317

318 Cordylus warreni barbertonenis (not Van Dam, 1921): FitzSimons, 1943: 426 (part: Hluti-

319 Goedgegun, Eswatini); Branch, 1988: 164 (part) \& 1998: 195 (part); Jacobsen, 1989 (part:

320 Godlwayo; Nzulase; Farm Zwartkloof 60 HU); Adolphs, 1996: 15 (part); Bourquin, $2004: 96$

321 (KwaZulu-Natal); Adolphs, 2006: 22 (part). 
322

323

324

325

326

327

328

329

330

331

332

333

334

335

336

337

338

339

340

341

342

343

344

345

346

347

348

349

350

351

352

Smaug warreni barbertonensis (not Van Dam, 1921): Stanley et al., 2011: 64 (part); Bates et al., 2014: 211 (part, including fig. on p. 211); Reissig, 2014: 190 (part, including figs 215-217, 219).

Smaug sp. Stanley \& Bates, 2014: 905.

Smaug cf. barbertonenis Mouton et al., 2018: 464.

Holotype. NMB R9201 (Fig. 5-7; sample from this specimen was used in molecular analysis by Stanley \& Bates, 2014), adult male (differentiated glandular femoral scales present; mid-ventral

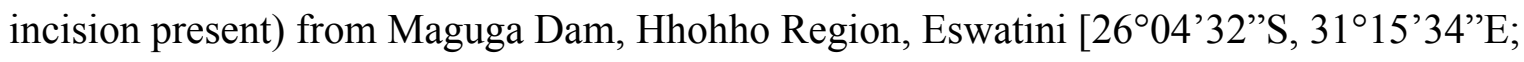

2631AB; 562 m a.s.1.], collected by E.L. Stanley \& J.M. da Silva, 31 October 2008.

Paratypes. Allotype: TM 78918 (Fig. 2), adult female (no differentiated femoral scales) from Nkomati Gorge, Malolotja Nature Reserve, Hhohho Region, Eswatini [2603'15'S, 31 $08^{\circ}$ '06"E; 2631AA; 640 m a.s.1.], collected by R.C. Boycott, 29 August 1993 (Fig. 2). Ten more paratypes:

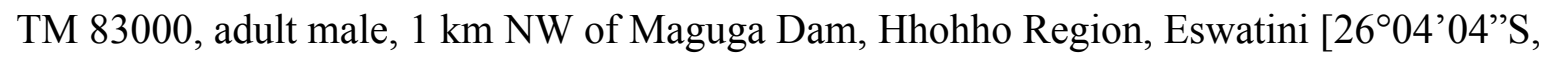
31 ${ }^{\circ} 14^{\prime} 55^{\prime \prime E}$; 2631AA; 618 m a.s.1.], R.C. Boycott, 25 March 1997; TM 83532, adult male, 5 km SE of Bhunya, Eswatini [2632'16”S, 31 ${ }^{\circ} 02^{\prime} 54$ 'E; 2631CA; $960 \mathrm{~m}$ a.s.1.], R.C. Boycott, 28 June 2000; TM 42531, adult female, Mbutini Hills, 23 km N of Sepofaneni, Eswatini [26³1'34”S, 31 $35^{\prime} 45^{\prime}$ 'E; 2631DA], W.D. Haacke, 3 September 1972; TM 51376, adult male, $15 \mathrm{~km}$ NW of Gilgal on route to Manzini, Lubombo district, Eswatini [2631DA], W.D. Haacke, 3 September 1972; TM 78931, juvenile, Nkomati Gorge, Malolotja Nature Reserve, Hhohho Region, Eswatini

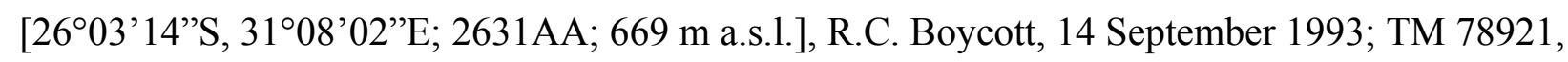
juvenile, Nkomati Valley, Hhohho Region, Eswatini [2603'12"S, 31 '14'24”'E; 2631AA; $580 \mathrm{~m}$ a.s.1.], J. Linden, 31 October 1992; NMB R9194, adult male, Komati View Point, Malolotja Nature Reserve, Hhohho Region, Eswatini [2604'29”S, 3107'32”E; 2631AA; 1033 m a.s.l.], E.L. Stanley \& J.M. da Silva, 31 October 2008 (Fig. 8B, C); NMB R9195, adult male, Komati

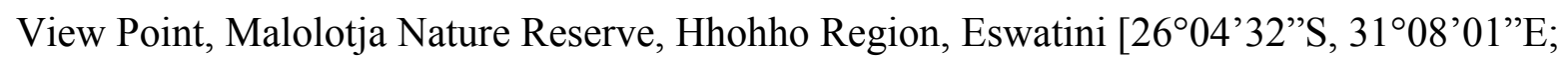
2631AA; 1052 m a.s.1.], E.L. Stanley \& J.M. da Silva, 31 October 2008; NMB R9202 (midventral incision present; sample from this specimen was used in molecular analysis by Stanley \& Bates, 2014), adult male from Maguga Dam, Hhohho Region, Eswatini [260.'32"S, $31^{\circ} 15^{\prime} 35^{\prime \prime}$; $2631 \mathrm{AB} ; 562 \mathrm{~m}$ a.s.l.], collected by E.L. Stanley \& J.M. da Silva, 31 October 2008; 


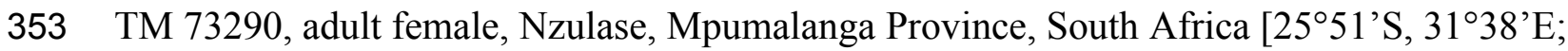

354 2531DC], N.H.G. Jacobsen, 29 March 1983.

355

356

357

Additional records (*material examined). SOUTH AFRICA: KwaZulu-Natal. Godlwayo Hill

358 (2720'S, 31 $25^{\circ}$ 'E; 750 m a.s.1.) TM 73290-1*, 73294*; Ithala Game Reserve (central point for 358

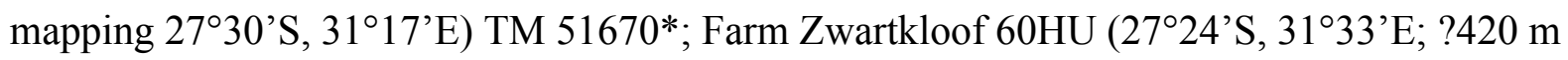
359 a.s.1.) TM 73285*. ESWATINI: between Hluti and Goedgegun [now called Nhlangano] (no coordinates) TM 16827-9*, 16798*; same locality $\left(27^{\circ} 12^{\prime} 20.1^{\prime \prime} \mathrm{S}, 31^{\circ} 20^{\prime} 10.5^{\prime \prime} \mathrm{E}\right.$, photographic 361

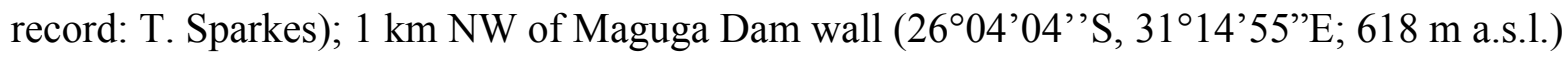
362 DNSM 1707 (identified as Smaug barbertonensis by R.C. Boycott, pers. comm.), TM 83002*; 1

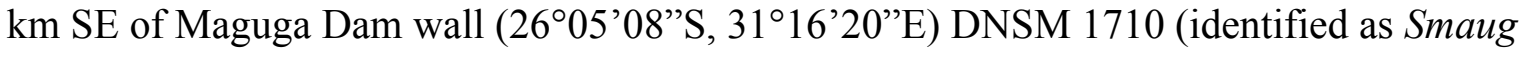

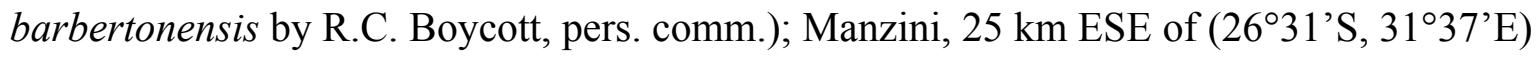
NMZB-UM 2026, 2529 (identified as Cordylus warreni barbertonensis by D.G. Broadley, pers. comm. - scalation details below); Nwempisi Gorge, $12 \mathrm{~km}$ E of Mankayane (26 42'13.4"'S, 31'11'49.1'E, sight record: R.C. Boycott). NO DATA: AMNH-R173382 (used for CT scanning).

369

370

Diagnosis. (includes 'additional material') Distinguished from all other cordylids (Cordylidae) by its unique dorsal, lateral and ventral colour patterns (see descriptions and figures). Referable

372 to the genus Smang on the basis of its large size and robust body, enlarged and spinose dorsal 373 and caudal scales, enlarged occipital scales, and frontonasal in contact with the rostral, separating 374 the nasal scales.

375 A medium to large species of Smang distinguishable by the following combination of characters: (1) back dark brown usually with 5-6 pale bands (usually interrupted) between fore- and hindlimbs, each band consisting of pale, sometimes dark-edged markings (2) pale band on nape behind occipitals; (3) flanks with large pale spots or blotches; (4) belly pale with a dark median longitudinal band bordered on either side by broad, dark, bands; (5) throat pale with extensive bold brown mottling (sometimes forming transverse bands; most of throat is dark) (6) six enlarged, moderately to non-spinose occipital scales, middle pair the smallest, outer occipitals 
384 moderately spikey; (9) dorsal scale rows transversely $31-41$; (10) dorsal scale rows

385 longitudinally 20-26; (11) ventral scale rows transversely 23-29; (12) ventral scale rows

386 longitudinally 14 (rarely 12); (13) femoral pores per thigh 10-13; subdigital lamellae on 4th toe 387 16-19.

388

389

Its status as a new species is also supported by monophyly with high levels of support from three

390

391

mitochondrial and eight nuclear markers (see Stanley \& Bates 2014; using samples from NMB

392

393 It differs from the terrestrial $S$. giganteus by its smaller adult size (maximum SVL $145 \mathrm{~mm}$

394 versus $198 \mathrm{~mm}$ ), and possession of six (occasionally four) moderate sized and weakly spinose

395 occipitals, versus four (occasionally five) large and distinctly spinose occipitals. Differs from

396 other species of Smang as follows: from $S$. vandami by usually having six (versus usually four)

397 occipitals; from $S$. depressus by having only 10-13 (versus 16-24) femoral pores per thigh in

398 males; and from $S$. breyeri by having much less rugose head shields. It differs from S. giganteus,

$399 S$. breyeri and S. vandami by having less spinose occipitals and tail spines, and two-layer (rather

400 than multi-layer) generation glands. Differs from S. mossambicus and S. regius by having the

401 first supralabial with moderate or no (versus distinct) upward prolongation, and lacking obvious

402 sexual dichromatism (only males of the latter two species have bright yellow to orange flanks).

403

404

405

406

407

408

409

410

Most similar to S. barbertonensis and S. warreni, but easily distinguishable by its colour pattern (as described above ) compared to S. barbertonensis (back dark brown with 4-5 pale bands, pale spot or blotch on nape behind occipitals; flanks dark with narrow pale vertical markings; venter mostly dark brown or black) and $S$. warreni (back usually pale brown with 5-6 pale dark-edged bands, pale band on nape behind occipitals; flanks pale with brown markings; venter with brown markings on most scales) (Figs 2, 6, 8, and others below); by usually having short, blunt, non-spinose scales at the edges of the ear openings (usually elongate and spinose in S. barbertonensis); and quadrates with a pronounced ridge and concave region at the lateral edge

412 of the adductor musculus mandibulae posterior origin (no pronounced ridge or concave region in 413 the other two species). Also differs as follows: outer occipitals shorter than the adjacent inner 414 ones (of about equal length in $S$. warreni); head narrower than S. barbertonensis (head 
415 width/head length $=76-84 \%$ versus 80-92\%); generally higher numbers of transverse dorsal

416 scale rows (32-37 in $86 \%$ of specimens) than $S$. barbertonensis (29-32 in $81 \%$ of $S$.

417 barbertonensis).

418

419 Description of holotype. NMB R9201. External morphology: Snout-vent length 138.8 mm, tail 420 length (original) $187 \mathrm{~mm}$, total length $325.8 \mathrm{~mm}$, head length $40.2 \mathrm{~mm}$, head width $31.2 \mathrm{~mm}$, 421 head depth $16.2 \mathrm{~mm}$. Tail length $/ \mathrm{SVL}=135 \%$; head width $/ \mathrm{SVL}=22.4 \%$; head width $/$ head 422 length $=77.5 \%$; head depth $/$ head length $=40.3 \%$. Head strongly depressed, head shields rugose 423 and moderately striated over parietal region. Frontonasal 1.05 times as wide as long, in contact 424 with the rostral and loreals, separating the nasals, latter slightly swollen. Nostril - with a large 425 inner flap attached posteriorly - situated in the posterior part of the nasal and in contact with the 426 loreal and 1st supralabial. Prefrontals in contact at their inner angles, separating the frontal from 427 the frontonasal. Frontal hexagonal, slightly widened anteriorly, anterior sides curved slightly 428 inwards. Frontoparietals slightly broader than long. Posterior parietals larger than anterior ones; 429 interparietal between four parietals, more sharply pointed anteriorly than posteriorly. Occipitals scales 6, well-developed, bluntly spinose, the outer ones shorter and smaller than the second ones, middle pair shortest and narrowest. Anterior upper temporals large, keeled at their lower edges. Gulars 23. Lateral temporals large, often bluntly keeled. Scales at anterior edge of ear opening ( 4 on left side of head, 5 right) projecting outwards as flattened and somewhat spatulate spines, the lowermost one narrow and slender, the one above it distinctly spatulate and the largest; middle scales somewhat short and blunt. Supraoculars 4, the anterior one longest, the next (2nd) one broadest, posterior one the smallest. Supraciliaries 4, anterior one the longest. Lower eyelid opaque, consisting of about 10 small, vertically-elongated scales. Preocular at least twice the size of the loreal. Five large scales below the eye. Rostral 2.04 times wider than deep. than above). Mental 1.36 times as wide as long. Infralabials 6, 5th and 6th keeled, bordered 441 below by five large sublabial shields. First pair of sublabials separated by an elongated scale in 442 contact with the large mental and followed behind by two pairs of similar-sized scales, and numerous small elongated scales that increase in size until about the middle of the throat, but

444 then reduce in size posteriorly. Sides of neck with irregular erect spines, the largest about twice 445 as high as wide. Dorsal scales large, rugose, often striated, forming regular (but not always 
446 aligned) transverse series; four vertebral rows with smooth scales (probably due to rubbing 447 against rocks), other dorsals keeled, but lateral scales keeled and spinose. Dorsals in 34 448 transverse series (from first row posterior to occipitals to row above vent) and 20 longitudinal 449 rows. Ventrals smooth, mostly quadrangular, occasionally pentagonal near middle of venter 450 posteriorly, mostly broader than long, two outer rows moderately keeled and weakly spinose, 451 some scales of the 3rd row also weakly keeled, forming 14 longitudinal and 26 transverse series 452 from axil to groin (with an additional seven rows to base of throat). A pair of slightly enlarged 453 hexagonal preanal plates (slightly longer than wide), with smaller plates anteriorly and on the 454 sides. Limbs above with large, keeled, spinose scales. Femoral pores 21 (10 left leg, 11 right). 455 Differentiated femoral scales 46 (21 left, 25 right). Fourth toe on each foot with 16 subdigital 456 lamellae. Tail with whorls of large, strongly keeled, spinose scales; each whorl separated by a 457 smaller whorl of small, moderately keeled and weakly spinose scales; two upper lateral caudal 458 scale rows consist of especially large and very strongly spinose scales (spines project backwards 459 at angles of about $45^{\circ}$ ); subcaudal scales long, narrow, mostly pentagonal (occasionally 460 rectangular) and moderately keeled.

461

462 Colour: (similar in life and in preservative; Fig. 6) Back dark brown to black with cream to 463 yellow markings forming five interrupted transverse bands (with only slightly dark borders in 464 preservative) between fore-and hindlimbs, which continue along the tail, together with a band 465 immediately behind the occipitals and another on the nape that is divided medially and curved 466 slightly backwards. Belly cream with a brown longitudinal band medially (six ventral plates 467 wide) and short, broad, widely separated brown bands on either side between the limbs (at least 468 four on the left, three on the right) which are often confluent with the darker parts of the back. 469 The joining of these dark ventral and dorsal markings decorates the flanks with large cream470 yellow spots/blotches. Top of limbs dark brown with numerous irregular cream to yellowish 471 spots and blotches; underparts of limbs mostly cream with irregular brown markings, 472 occasionally bands. Top of head brown with scattered irregular cream markings; throat mottled 473 in dark brown and cream, the dark markings forming four irregular, wavy transverse bands.

474

475 Cranial skeleton: (Fig. 7) Scales of the dorsal and temporal regions of the skull and the 476 ventrolateral aspects of the jaws are underlain with rugose osteoderms. These osteoderms fuse to 
477 the proximal parietal, frontal and postorbital bones, although the mesokinetic and metakinetic 478 joints appear unobstructed and flexible. Lateral maxilla and anterior aspect of the premaxilla lack 479 osteoderms. The parietal is pentagonal, with five osteoderms that underlie the parietal shields 480 fused to its dorsal surface, and a bifid medioposterior process that extends either side of the sagittal crest of the supraocciptial. Three large osteoderms are fused to the frontal, which is unpaired and clasped by the parietal at its posterolateral edge. The upper temporal fenestra is obscured anteriorly by a large osteoderm fused to the dorsal surface of the postorbital bone, posteriorly by an unfused rectagonal osteoderm that overlies the squamosal. Premaxilla is unpaired and contains seven pleurodont teeth and five foramina, with a dorsal process that extends posteriorly to be clasped by the nasals, which themselves insert into the frontal. The maxilla is scinciform, with a deeply grooved crista dentalis, 9 left or 8 right lateral foramina, and 19 teeth. Teeth display pleurodont attachment and are unicuspid, with a slight concave surface where they connect with the mandibular teeth. No palpebral is present and the prefrontal connects directly to the anteriormost superorbital osteoderm. The jugal is triangular in crosssection and asymmetrically T-shaped, with a tapering anterior process and a broad, truncated posterior process that extends along and past the posterior edge of the maxilla. Lacrimal bone is small, flattened and oval. Pterygoids are edentate and extend back to connect with the quadrates, becoming C-shaped in cross-section posterior to the epipterygoid condyle. The squamosal is curved and blade-like, circular in cross-section anteriorly, becoming flattened posteriorly, where it articulates with the cephalic condyle of the quadrate and the braincase. Supratemporals are flattened, ovoid and not fused with the elongate paroccipital processes. The posterior aspect of the prootic not fully fused with the oto-ocipital, resulting in a deep groove along the dorsal aspect of the para-occiptal processes. Quadrates very broad with a pronounced ridge and concave region at the lateral edge of the adductor musculus mandibulae posterior origin. The supraoccipital has a strong sagittal crest that extends posteriorly to contact the ventral surface of the medioposterior process of the parietal. The prootic bears an extended alar process and a welldeveloped, rhomboid christa prootica, and a very weak supratrigeminal process. Basipterygoid processes are well developed and flattened. The lower jaw possesses a large adductor fossa, a highly flattened and medially extended retroarticular process, a medially open Meckelian canal that is closed posteriorly by a large splenial, and a dentary with a strong subdental shelf; 21 mandibular teeth, and nine dentary foramina. 
508

509 Postcranial skeleton: (Fig. 7) Tail complete, 26 presacral vertebrae, 32 caudal vertebrae. The 510 haemapophyses of the first caudal osteoderms extend laterally to fuse to the posteroventral edge

511 of the parapothysis, forming a biphid rib. Four cervical, three sternal, two xiphisternal, 6 left and

5127 right long asternal ribs with ossified costal cartilage, then 6 left and 5 right short asternal ribs

513 and one very short pair of ribs immediately anterior to the sacral vertebrae. Cervical ribs $2-4$ are

514 distally flattened and biphid, with the ventral processes more elongated. Pubis flattened and

515 curved with a large, ventrally angled pectineal tubercle. Pubic symphysis flattened and

516 triangular, separating the pubes entirely. Hyperischiam and hypoischium well developed. Illium

517 triangular in cross-section, with a feeble iliac tubercle. Sternal plate broad with no fontanelle.

518 Interclavicle cruciform, clavicles flattened dorsally. Epicoracoid connects the scapular ray to the 519 primary and secondary coracoid rays, but not to the anterior process of the scapular. Phalanges

520 display a typical pattern of 2-3-4-5-3 for the manus and 2-3-3-5-4 for the pes. Metatarsal 5

521 with elongated medial process at midbody.

522

523

Dermal osteology: (Fig. 7) Dorsal and lateral sides of the trunk are covered in circular, well-

524 separated osteoderms, dorsomedially unkeeled grading to well keeled and mucronate towards the

525 sides. The nuchal osteoderms are small, becoming highly spined posterior to the tympanic

526 opening. Ventral osteoderms are delicate and plate-like, and restricted to the gular and anterior

527 pectoral regions. The forelimbs are covered in keeled non-imbricate circular/ rhomboid

528 osteoderms, while the hindlimbs are well armoured, except for the ventral surface of the thigh,

529 which lacks osteoderms. Osteoderms on the posterior part of the hindlimbs are heavily spinose.

530 The caudal osteoderms are large, robust and arranged in imbricated whorls. Caudal osteoderms

531 are feebly keeled and mucronate along the dorsal and ventral aspects, becoming more heavily

532 spined laterally.

533

534 Variation in paratypes (including allotype TM 78918; Fig. 2). External morphology: (Tables 2, 535 3) Tail length/SVL 112-144\% (SVL: 129.4-143.8 mm, $N=3$ ); head width/SVL = 21.6-23.9\% in males (SVL: 129.4-145.0 mm, $N=5$ ), 20.3-23.1\% in females (SVL: 102.8-143.8 mm, $N=$

537 4); head width/head length $=78.3-82.7 \%$ (SVL: 102.8-145.0 mm, $N=9)$; head depth/head 538 length $=41.9-48.7 \%$ (SVL: $102.8-145.0 \mathrm{~mm}, N=9)$. In TM 78918, shields on anterior part of 
539 head smooth, weakly rugose on posterior part of head but without striations; in two juveniles:

540 head shields smooth (TM 78921) or weakly rugose without striations (TM 78931). Frontonasal

$541 \quad 0.89-1.12$ (0.94-1.05 in juveniles) times as wide as long. Nasal scale fragmented on left side in

542 TM 83000. Small infranasal present on both sides of head in TM 78918. Frontal with anterior

543 sides straight in TM 78921, strongly curved inwards in NMB R9202, separated from rostral by a

544 small rectangular scale in TM 42531. Prefrontals in narrow contact in TM 51376, anterior half of

545 prefrontals in contact in TM 78918 and 83532 . Frontoparietals about as wide as long in TM

$54673290,78918,78931$ and 83532. Interparietal sunken in NMB R9195, about as large as an

547 anterior parietal in two juveniles (TM 78921, 78931), triangular in TM 51376 and 73290, and as

548 pointed posteriorly as it is anteriorly in TM 83000 and 83532 . Occipitals 6 but middle pair

549 separated by a small elongate scale in TM 78931, mostly very weakly spinose, all of about the

550 same size in TM 78918, outer scale and the one adjacent to it of similar length in NMB R9202

551 and TM 73290; in TM 83532 scales of the middle pair are shortest but of similar width to the

552 others, and wider than the outer occipitals; but the middle and outer scales may be similar in size

553 (TM 42531, 51376); middle occipitals the same size as second occipitals on either side in TM

55478931 ; on left side of TM 83000 the outer occipital is about equal in size to the occipital adjacent

555 to it; in TM 51376 the inner occipitals are rugose only, not spinose. Gulars 22-28 (25 in

556 allotype). Posterior upper temporal scale keeled at its lower edge in TM 42531, 78918 and

557 78921; anterior and posterior upper temporals similar in size and keeled at the sides in TM

558 51376. Lateral temporals rugose only (not keeled) in NMB R9194 and TM 51376. Scales at

559 anterior edge of ear opening 4-6 (3rd from the top is tiny in TM 83532), lowermost spine often

560 not slender and similar to other small spines, but elongate and distinctly spiny in TM 42531. First

561 and 2nd (TM 78921, 78931) and 1st and 3rd (TM 78918) supraoculars about the same length,

562 2nd and 3rd on left side of NMB R9194 largely fused. Supraciliaries 5 (left side: NMB R9202,

563 TM 42531; right: TM 83532), first and second supraciliaries about equal in length in TM 78931.

564 Lower eyelid transparent in TM 73290 and TM 83532, usually consisting of several irregular

565 scales (e.g. NMB R9195). Preocular about 1.5 times (TM 42531, 51376, 83532) and 1.75 times

566 (TM 73290) larger than loreal. Six large scales below the eye in TM 42531, TM 73290 (left) and

567 TM 78931 (left), and four in TM 83000; large suborbital shield divided in TM 73290. Rostral

568 2.14-2.81 (1.87-2.10 in juveniles) times wider than deep. Supralabials 7 on left side of head in

569 TM 73290 and TM 78921; sixth (of six) in TM 51376 is granular and 2nd is fragmentary; 4th (of 
570 6) distinctly keeled in TM 42531; 3rd and 4th fused in NMB R9202. Mental 1.17-1.66 (1.16 in 571 juvenile TM 78931) times as wide as long. Fourth and 6th infralabial weakly keeled in TM 572 78931. Fifth and most posterior sublabial on either side of head rugose and keeled (TM 73290, 573 78918); 1st pair of sublabials in contact (NMB R9202; TM 78918, 78921, 78931, 83000, 83532), 574 or separated by a narrow groove (TM 51376), large rectangular scale (NMB R9194), elongated 575 triangular scale (NMB R9195), or separated posteriorly by a tiny pair of granules (TM 73290); 576 1st pair of sublabials followed by three (not two) pairs of smaller, slightly enlarged scales in TM 577 78931, and by one pair of distinctly enlarged scales in NMB R9202. Spines on sides of neck only 578 about 1.5 times (not twice) as high as wide in juveniles (TM 78921, 78931) and TM 83000.

579 Dorsal scales of TM 78918 and 78931 with short folds rather than distinct striations; two 580 vertebral scale rows smooth in TM 42531, 4-6 rows smooth in TM 83532, 6-8 rows smooth in 581 NMB R9195, none smooth in TM 83000, all vertebrals keeled in juveniles. Dorso-lateral and 582 lateral scales usually keeled and spinose, but weakly spinose in juveniles. Dorsals in 32-41 (34 583 in allotype) transverse, and 21-26 (21 in allotype) longitudinal, rows. Ventrals occasionally 584 pentagonal (TM 73290, 78918, 83532), longer than broad on anterior part of belly (TM 73290, 585 78918) or mostly square (NMB R9195, TM 51376 and 83000). All ventrals smooth in TM 586 51376; in NMB R9194 and TM 83532 only the outermost row of ventrals is moderately keeled 587 and weakly spinose, with rows 2-3 very weakly keeled only; some scales of the 3rd row also 588 very weakly spinose in NMB R9194 (including first inner row) and TM 73290, 78918, 83000; 589 all three outer rows weakly keeled in NMB R9195. Ventrals in 23-29 (28 in allotype) transverse 590 rows (6-9 additional rows on throat), and occasionally only 12 (NMB R9194, TM 51376) 591 longitudinal rows. Enlarged hexagonal preanal plates 3 (TM 78918) or 4 (TM 83532); median 592 preanal plates (pair) pentagonal in TM 42531, 51376, 78931 and 83000, heptagonal in TM 59373290 (left side) which also has two extranumerary plates posterior to the large pair, and 594 irregular in TM 78921; no enlarged plates anterior to median and lateral plates in TM 78931; 595 enlarged median pair of plates in TM 42531, 51376, 78931 and 83000 much elongated, about 596 twice as long as wide. Femoral pores 20-24 (10-12 on each thigh, 10 in allotype), appearing as 597 small, shallow pits in females. Differentiated glandular femoral scales in males 19-61 (9-35 per 598 thigh). Fourth toe with 16-19 (18 in allotype) subdigital lamellae. 
600 Colour: Dorsum dark brown to black in preservative. Back with 4-6 (usually 5) interrupted 601 transverse bands between fore- and hindlimbs, which are without dark borders or with only 602 feeble indications thereof after preservation in alcohol. In TM 73290 there is a squarish cream 603 spot on the nape between the pale band behind the occipitals and the band on the neck. Belly 604 with 5-6 brown crossbands on either side of the median band (comprised of at least six 605 longitudinal rows of ventrals, sometimes eight at places [e.g. TM 51376]) which is prominent in 606 the centre of the belly. Throat with bold, dark mottling or reticulations; occasionally some 607 markings form transverse bands, and sometimes most of the throat is black, especially anteriorly 608 (e.g. NMB R9195 and TM 83532).

609

610 Variation in additional material. (All localities in KwaZulu-Natal; material examined only for 611 the characters listed below.) External morphology ( $N=10$ unless otherwise indicated): Tail 612 length/SVL 1.35-1.42 (SVL: 97.9-132.7 mm, $N=3$ ); head width/SVL $=23.3-24.6 \%$ in males 613 (SVL: 97.9-130.7 mm, $N=3$ ), 21.4-22.7\% in females (SVL: 123.9-132.7 mm, $N=3$ ); head 614 width/head length $=76.2-83.9 \%($ SVL: $97.9-132.7 \mathrm{~mm}, N=6)$; head depth/head length $=$ $61536.2-47.6 \%$ (SVL: 97.9-132.7 mm, $N=6$ ). Preoculars 1; supraoculars $4(N=9)$; supraciliaries 4 616 (3 on right side in TM 73294; $N=8$ ); postnasals $1(N=9)$; suboculars 4-5 (4 left, 5 right in TM 617 83002); supralabials (anterior to median subocular) usually 4 (5 in TM 16828; $N=9$ );

618 infralabials $6(N=9)$; sublabials 5 (4 on left side in TM 16827; N=9); occipitals 6 (additional 619 small median scale in TM 16798 and 83002); gulars 24-29 $(N=9)$; frontal and frontonasal in 620 broad contact in TM 16798; scales at anterior edges of ear openings elongate and distinctly 621 spinose (rather than short and blunt) in TM 16828; dorsal rows transversely 31-38; dorsal rows 622 longitudinally 21-24; ventral rows transversely 25-27 $(N=9)$; ventral rows longitudinally 623 usually 14, but 12 in TM 73285 and 773291; femoral pores per thigh 11-13 (males, $N=4$ ), 624 10-13 (females, $N=6$ ); differentiated femoral scales (generation glands) in males 19-29 per 625 thigh $(N=3)$; lamellae under fourth toe 16-19.

626 For the two Eswatini specimens (NMZB-UM 2026, 2529) examined by D.G. Broadley: 627 occipitals 6; dorsal scale rows transversely 36 and 38 respectively, longitudinally 22; femoral 628 pores/thigh 10.

629 
630 Colour: Similar to holotype. Back with 5-6 (4 in TM 73285) interrupted transverse bands

631 (sometimes with slightly dark borders in preservative). Belly with 5-6 brown crossbands on 632 either side of the median band (prominent in the centre of the belly). Throat with bold, dark 633 mottling or reticulations; occasionally some markings form transverse bands.

634

635 Size. Largest male (NMB R9194 [paratype], Komati View Point, Eswatini) $140.0+202=342$

$636 \mathrm{~mm}$, but NMB R9195 (paratype, Komati View Point) has SVL of $145.0 \mathrm{~mm}$ (tail

637 broken/missing). Largest female (TM 78918 [allotype], Nkomati Gorge, Eswatini) $143.8+161=$ $638305 \mathrm{~mm}$.

639

640 Etymology. Named for the Kingdom of Eswatini, the country where most of the species' range 641 is located. Both 'eSwatini' and 'Swaziland' derive from the word iSwazi, after the name of an 642 early chief, Mswati II (c. 1820-1868).

643

644 Distribution. Highveld and Middleveld regions of Eswatini, and adjacent areas in the South 645 African provinces of (eastern) Mpumalanga (in Nkomazi municipality) and (northern) KwaZulu646 Natal (in uPhongolo and Abaqulusi municipalies) (Fig. 9) at elevations of 462 to $1052 \mathrm{~m}$ a.s.l.

647

648 Natural history. Diurnal and rupicolous, living in deep, horizontal (or gently sloping) crevices 649 in granitic rock along hillsides, usually in the partial shade of trees (Fig. 8A; see also Jacobsen, 650 1989). According to R C Boycott (in litt., 2019), rocky terrain in closed canopy bushveld is the 651 preferred habitat in Eswatini. A specimen in Ithala Game Reserve in KwaZulu-Natal was 652 photographed on a tree trunk (ReptileMAP, VM no. 152451). When grasped by the hind limb, an 653 individual from the type series performed an unusual anti-predator behaviour by repeatedly 654 flexing and extending the inhibited limb caudally, so as to pull the captors' digits directly onto 655 the very sharp whorl of spines at the base of the tail (ELS pers. obs.).

656

657 Note. The photograph of a specimen of 'Smaug warreni barbertonensis' from 'Barberton' in 658 Bates et al. (2014) is the same one used for Fig. 7 in the current paper (i.e. NMB R9194, 659 paratype of $S$. swazicus sp. nov.).

660 
661

662 Smaug barbertonensis (Van Dam, 1921)

663 Barberton Dragon Lizard

664 Figs 10-12, Figs S1-2

665

666

Zonurus barbertonensis Van Dam, 1921: 240 (Barberton) Holotype: TM 4273 (Figs S1,2);

667 Power, 1930: 14 \& 17 (Barberton).

668 Zonurus barbertonensis barbertonensis FitzSimons, 1933 (by implication after describing 669 Zonurus barbertonensis depressus).

670 Cordylus warreni barbertonensis FitzSimons, 1943: 426 (part, Barberton and Nelspruit);

671 Loveridge, 1944: 20 (Barberton); Branch, 1988: 164 (part), 1998: 195 (part); Jacobsen, 1989:

672590 (part: 5 km S of Nelspruit; Barberton Townlands 369JU; Broedershoek 129JU;

673 Friedenheim 282JT; Karino to White River; Khandizwe; Nelspruit); Adolphs, 1996: 15 (part)

674 \& 2006: 22 (part);

675 Smaug warreni barbertonensis Stanley et al., 2011 (part); Bates et al., 2014: 211 (part, but

676 excluding fig. on p. 211); Reissig, 2014: 190 (part, including fig. 218).

677 Smaug barbertonensis Stanley \& Bates, 2014: 905; Mouton et al., 2018: 463.

678

679 Diagnosis. Distinguished from all other cordylids by its unique combination of dorsal, lateral 680 and ventral colour patterns (see descriptions and figures).

681

682 A medium to large species of Smaug distinguishable by the following combination of characters:

683 (1) back dark brown with 4-5 bands (usually interrupted) between fore- and hindlimbs, each 684 band consisting of pale, sometimes dark-edged markings; (2) pale spot or blotch on nape behind 685 occipitals; (3) flanks dark with narrow pale vertical markings; (4) belly mostly dark brown or 686 black; (5) throat almost entirely dark brown or black with only a few pale areas; (6) six enlarged, 687 moderately to non-spinose occipital scales, middle pair the smallest, outer occipitals usually 688 shorter than the adjacent inner ones; (7) dorsolateral scales weakly spinose; (8) tail moderately 689 spikey; (9) dorsal scale rows transversely 28-34; (10) dorsal scale rows longitudinally 20-24; 690 (11) ventral scale rows transversely 25-28; (12) ventral scale rows longitudinally 14 (rarely 16); 691 (13) femoral pores per thigh 8-12; subdigital lamellae on 4th toe 15-19. 
692

693 It differs from other species of Smaug as described above in the diagnosis of S. swazicus sp.nov.

694 (but maximum SVL in S. barbertonensis is $140 \mathrm{~mm}$, and femoral pores in males are 8-11).

695

696

697

Most similar to $S$. swazicus sp. nov. and $S$. warreni, but easily distinguishable by its colour 698 pattern (see comparisons in diagnosis of S. swazicus sp. nov. above); by usually having more 699 elongate and spinose scales at the edges of the ear openings (shorter and non-spinose in $S$. 700 swazicus sp. nov. and $S$. warreni); and quadrates lacking a pronounced ridge and concave region 701 at the lateral edge of the adductor musculus mandibulae posterior origin (with a pronounced

702 ridge and concave region in S. swazicus sp. nov.). Also differs as follows: outer occipitals 703 shorter than the adjacent inner ones (of about equal length in $S$. warreni); head relatively wider

704

705

706

707

708

709

710

711

712

713

714

715

716

717

718

719

720

721

722

than the other two species (head width/head length $=80-92 \%$ versus $73-84 \%$ ); lower numbers of transverse dorsal scale rows (29-32 in 81\%) compared to S. swazicus sp. nov. (32-37 in 86\%) and $S$. warreni (32-38 in 92\%); and lower numbers of longitudinal dorsal scale rows (20-24, mean 21.7) compared to $S$. warreni (22-28, mean 23.6).

Variation. ( $N=26$ unless otherwise indicated) External morphology: (Fig. 10) Tail length/SVL 121-142\% (SVL: 109.6-134.0 mm, $N=7$ ); head width/SVL = 22.5-25.7\% in males (SVL: 111.0-134.0 mm, $N=9$ ), 20.9-24.1\% in females (SVL: 109.6-139.9 mm, $N=11$ ); head width/head length $=80.4-92.0 \%($ SVL: 109.6-139.9 mm, $N=20)$; head depth/head length $=$ $38.2-48.2 \%$ (SVL: $109.6-139.9 \mathrm{~mm}, N=20$ ). Frontonasal in contact with the rostral and loreals, separating the nasals, latter slightly swollen; nostril - with a large inner flap attached posteriorly - situated in the posterior part of the nasal and in contact with the loreal and first supralabial; frontal separated from the frontonasal by a pair of prefrontals $(N=4$, topotypes). Scales at anterior edge of ear opening 4-6 on either side of head, projecting outwards as flattened, somewhat spatulate spines, the lowermost one narrow and slender, the one above it distinctly spatulate and the largest; scales generally elongate and somewhat spinose (more so than in $S$. swazicus and S. warreni), but short and blunt in TM 55789, 73292 and three juveniles (TM 4275, 26643, 73286). Preoculars 1; postoculars 1; supraoculars 4; supraciliaries usually 4 (5 on one side in three specimens); postnasals 1; suboculars usually 4-6 (often different on either side of 
723 head), but 7 on left side in NMB R9192); supralabials (anterior to median subocular) usually 4 (3

724 on one side in three specimens, and 5 on one side in two specimens); infralabials usually 5-6 (5

725 on left and 7 on right in TM 73281, and 6 left and 7 right in TM 55787); sublabials usually 5 (6

726 in NMB R9192); occipitals usually 6 (7 in TM 4468 and 4472, 8 in TM 73284; NMB R9192 has

727 a single tiny median granule, TM 73293 has two such granules), outer occipitals shorter than

728 those adjacent to them and those of the median pair the shortest $(N=4)$; gulars $23-31$, but 20 in

729 NMB R9193; dorsal scale rows transversely 28-34, longitudinally 20-24; ventral scale rows

730 transversely 25-28, longitudinally usually 14 (16 in TM 73283); femoral pores per thigh 8-11

731 (males, $N=11$ ), 8-12 (females and juveniles, $N=15$ ); differentiated femoral scales (generation

732 glands) in males $\geq 100 \mathrm{~mm}$ SVL: $16-36$ per thigh $(N=10)$, in juvenile males $<66 \mathrm{~mm}$ SVL:

733 18-22 per thigh $(N=2)$; lamellae under fourth toe 15-19.

734

735 Colour: (Figs 2, 12B-C) Back dark brown to black with cream to yellow markings (mostly 736 transversely enlarged) forming 4-5 (usually 4, as in holotype TM 4273, Fig. S1) interrupted 737 transverse bands (usually with slightly dark borders in preserved material) that continue onto the 738 tail, together with a band on the nape and a cream spot, blotch or elongate marking (absent in 739 NMB R9193 and TM 73286) immediately behind the median occipitals. Belly mostly brown 740 (older preserved material; including the holotype, Fig. S2) to black (as in life) with a few cream 741 patches or short 'bands' on either side, which are occasionally joined to the pale bands on the 742 side of the back. The flanks are dark brown to black, usually with narrow, cream to yellowish, 743 vertically elongated bars, occasionally spots (e.g. TM 51066). Top of limbs with numerous 744 irregular cream to yellowish spots and blotches; underparts of limbs mostly cream with irregular 745 brown markings, occasionally bands. Top of head brown or black with scattered irregular cream 746 markings. Throat (including sublabials) mostly black or brown with occasional irregular

747 scattered cream markings, but about half dark and half pale in TM 73283 and 73293, and mostly 748 plain cream in TM 4275 (juvenile).

\section{9}

750

\section{Cranial skeleton, post-cranial skeleton and dermal osteology (Fig. 11)}

751 The cranial skeleton, post-cranial skeleton and osteoderms are all similar to those described for 752 S. swazicus sp. nov. However, in S. barbertonensis ventral osteoderms were absent, and 753 quadrates lacked a pronounced ridge and concave region at the lateral edge of the posterior 
754 origin of the adductor musculus mandibulae (quadrates have a pronounced ridge and concave

755 region in S. swazicus sp. nov.).

756

757 Size. Largest male (TM 73287, Broedershoek) $129.0+182.8=311.8 \mathrm{~mm}$, but TM 51066

758 (between Karino and White River) has SVL of $134.0 \mathrm{~mm}$ (tail broken/missing). Largest female

759 (TM 4273: holotype, Barberton) 134.0 + 175=309 mm, but TM 4468 (Barberton) has SVL of

$760139.9 \mathrm{~mm}$ (tail broken/missing).

761

762 Natural history. Diurnal and rupicolous, living in deep, horizontal (or gently sloping) crevices

763 in and between large granitic boulders, often in the partial shade of trees (Fig. 12A; see also

764 Jacobsen, 1989). For S. 'barbertonensis', FitzSimons (1943: 427) noted that the diet is similar to

765 that of $S$. warreni (see below), but includes cetonid beetles and small land snails; usually five

766 young are produced, and based on his examination of a series of females, fertilisation occurs in

767 early spring, with young born at the end of summer. However, one of FitzSimons' (1943)

768 localities ('Hluti-Goedgegun', Eswatini) is within the range of S. swazicus sp. nov., so it is not

769 possible to know which species his data applies to. Computed Tomography scanning of NMB

770 R9192 revealed four large embryos, and a large beetle in the stomach.

771

772 Distribution. Restricted to the Barberton, Nelspruit and Khandizwe areas of eastern

773 Mpumalanga Province, South Africa (Fig. 9) at elevations of 724 to $1008 \mathrm{~m}$ a.s.1. An isolated

774 record for this species at Farm: Jessievale, Ermelo district (2630AB, Bates et al., 2014) is in fact

775 referable to Cordylus vittifer (re-examination by both authors of VM no. 1400 on ReptileMAP).

776

777 Localities. SOUTH AFRICA: Mpumalanga Province. Barberton (2547'S, 31 03 'E) TM 4273-

778 5, 4468-9, 4471-2; Barberton army base - NMB R9191, 9196 (2546’26”S, 3103'20”E; $861 \mathrm{~m}$

779 a.s.1.), NMB R9192-3 (2546'27’S, 3103'21'E; $861 \mathrm{~m}$ a.s.1.); Barberton Townlands (2547'S,

$\left.78031^{\circ} 03 \mathrm{E}\right) \mathrm{TM} 73281,73283-4$; Broedershoek $129 \mathrm{JU}\left(25^{\circ} 27^{\prime} \mathrm{S}, 31^{\circ} 07^{\prime} \mathrm{E}\right.$; $753 \mathrm{~m}$ a.s.1.) TM

781 73286-7; Friedenheim 282JT (252ㅇ'S, 3059'E; $754 \mathrm{~m}$ a.s.1.) TM 55787; Karino and White

782 River, between (2531AC) TM 51066; Khandizwe (25²8'S, 31 225'E; $724 \mathrm{~m}$ a.s.1.) TM 73292-3;

783 Nelspruit, $5 \mathrm{~km} \mathrm{~S}$ of (25³2’S, 3057’E; 824 m a.s.1.) TM 44873; Nelspruit, $14 \mathrm{~km} \mathrm{~W}$ of, on road 
784 to Machadodorp (2530BD) TM 26643; Nelspruit, 82 Ehmke Street, Extension 5 (Fig. 11);

785 Nelspruit, Van Riebeeck Park (2528’S, 3059’E) TM 55788-9.

786

787 Notes. Van Dam's (1921) type locality of 'Barberton' does not indicate the exact locality at

788 which the specimens were collected, so it is considered appropriate to treat both 'Barberton

789 Townlands' (Jacobsen, 1989) and 'Barberton army base' as topotypic.

790

791

792 Smaug warreni (Boulenger, 1908)

793 Lebombo Dragon Lizard

794 Figs 13-15

795

796

Zonurus warreni Boulenger, 1908: 232 (Ubombo) Syntype: NHM 1946.8.8.1 (see Reissig 2014:

797 187); Hewitt, 1909: 36; Boulenger, 1910: 467 \& 468; Power, 1930: 14 \& 17; FitzSimons,

798 1930: 30; Lawrence, 1937: 111.

799

Cordylus warreni warreni FitzSimons, 1943: 424 (Ubombo \& Ingwavuma); Loveridge, 1944: 19

800 (Ubombo); Branch, 1988: 164, 1998: 195; Jacobsen, 1989: 586 (Duikershoek,

801 Halfkroonspruit, Jozini Dam, Mananga, The Hippos); Adolphs, 1996: 15; Bourquin, $2004: 96$

802 (KwaZulu-Natal); Adolphs, 2006: 22.

803 Cordylus warreni Alexander \& Marais, 2007: 261 (but photograph on p. 259 is of a Smaug

804 depressus, see same photograph in Bates et al. 2014: 212); Parera et al. 2011: 14.

805 Smaug warreni warreni Stanley et al., 2011; Bates et al., 2014: 210; Reissig, 2014: 187.

806 Smaug warreni Stanley \& Bates, 2014: 905; Mouton et al., 2018: 463.

807

808 Diagnosis. Distinguished from all other cordylids by its unique combination of dorsal, lateral 809 and ventral colour patterns (see descriptions and figures).

810

811 A medium to large species of Smaug distinguishable by the following combination of characters:

812 (1) back usually sandy brown with 5-6 bands (usually interrupted) between fore- and hindlimbs, 813 each band consisting of pale, dark-edged markings; (2) pale band on nape behind occipitals; (3)

814 flanks pale with brown markings; (4) belly with brown (often pale) markings on most scales; (5) 
815 throat usually mostly pale with scattered small brown spots; (6) six enlarged, moderately to non816 spinose occipital scales, middle pair the smallest, outer occipitals usually equal in length to the 817 adjacent inner ones; (7) dorsolateral scales weakly spinose; (8) tail moderately spikey; (9) dorsal 818 scale rows transversely $31-41$; (10) dorsal scale rows longitudinally 22-28; (11) ventral scale 819 rows transversely 23-27; (12) ventral scale rows longitudinally 14 (rarely 12 or 13); (13) femoral 820 pores per thigh 7-13; subdigital lamellae on 4th toe 15-20.

821

822 It differs from other species of Smaug as described above in the diagnosis of $S$. swazicus sp.nov. 823 (but maximum SVL in $S$. warreni is $141 \mathrm{~mm}$, and femoral pores in males are 7-13).

824

Most similar to $S$. swazicus sp. nov. and $S$. barbertonensis but easily distinguished by its 826 colour pattern (see comparisons in diagnosis of S. swazicus sp. nov. above); by usually having 827 shorter and blunter scales at the edges of the ear openings compared to S. swazicus sp. nov.; and 828 quadrates without a pronounced ridge and concave region at the lateral edge of the adductor 829 musculus mandibulae posterior origin (with a pronounced ridge and concave region in $S$. 830 swazicus sp. nov.). Also differs as follows: outer occipitals and scales adjacent to them of about 831 equal length (outer occipitals shorter than the adjacent inner ones in the other two species); head 832 narrower than $S$. barbertonensis (head width/head length $=73-83 \%$ versus $80-92 \%$ ); generally 833 higher numbers of transverse dorsal scale rows (32-38 in 92\% of specimens) than $S$.

834 barbertonensis (29-32 in 81\%); and greater numbers of longitudinal dorsal scale rows (22-28, 835 mean 23.6) than $S$. barbertonensis (20-24, mean 21.7).

836

837 Variation. External morphology ( $N=39$ unless otherwise indicated; Figs 13): Tail length/SVL 838 106-143\% (SVL: 105.0-128.9 mm, $N=6$ ); head width/SVL = 22.2-24.2\% in males (SVL:

$839105.3-127.3 \mathrm{~mm}, N=9$ ), 19.4-23.3\% in females (SVL: 100.6-141.1 mm, $N=21$ ); head 840 width/head length $=72.5-83.1 \%($ SVL: 100.6-141.1 mm, $N=30)$; head depth $/$ head length = $84135.0-47.2 \%$ (SVL: 100.6-141.1 mm, $N=31$ ). Frontonasal in contact with the rostral and loreals 842 (often in narrow contact, especially on right side in TM 50130), separating the nasals, latter 843 slightly swollen; nostril - with a large inner flap attached posteriorly - situated in the posterior 844 part of the nasal and in contact with the loreal and 1st supralabial (TM 50130: loreal in very 845 narrow contact with nostril on left side of head, and separated from nostril by upward 
846 prolongation of first supralabial on right; posterior part of both supranasals separated by a suture 847 to form a small rectangular scale) $(N=16)$. Frontal usually separated from the frontonasal by a 848 pair of prefrontals, but in broad contact in TM 47449, 50130 [Fig. 13], 50660-1 $(N=16)$ and 849 NMZB-UM 30514 (D.G. Broadley, pers. comm.). Scales at anterior edge of ear opening usually 850 4-5 (3 on right side of head of TM 63567) projecting outwards as flattened, somewhat spatulate, 851 spines, the lowermost one narrow and slender (especially so in TM 47449), the one above it 852 distinctly spatulate and the largest; middle scales usually somewhat blunt and rounded, but 853 generally long and somewhat spinose in TM 47449, 50130, 53869, $70961(N=16)$. Preoculars 1; 854 supraoculars 4 (2nd and 3rd on left side largely fused in NMB R10913); supraciliaries usually 855 4-5 (3 on left side of TM 78967, 4 left and 6 right in TM 13639, 6 on left side of 78969); 856 postnasals 1; suboculars usually 4-5, occasionally 6; supralabials (anterior to median subocular) 857 usually 4 ( 3 on one side in four specimens, 5 on one side of TM 78967); infralabials usually 6 (5 858 on both sides of TM 582,5 on one side of TM 47449, 7 on both sides of TM 15320, 7 on one 859 side in six specimens); sublabials 5; occipitals usually 6, but an additional - often narrow and 860 much elongated - scale medially in 41\% of specimens (median scale large in TM 50660, 861 granular in TM 78966); outermost occipitals and those adjacent to them of similar size and 862 length, but scales of the inner pair shorter and often smaller, except in NMB R10878 in which all 863 occipitals are of similar length, although those of the inner pair are wider $(N=16)$; gulars 23-32 $864(N=37)$; dorsal scale rows transversely $31-41$, longitudinally $22-28$; ventral scale rows 865 transversely 23-27, longitudinally usually 14 (13 in NMB 9199, 12 in TM 2808 and 78969); 866 femoral pores 7-13 (males [smallest is $86.2 \mathrm{~mm} \mathrm{SVL}$ ], $N=11$ ), 8-13 (females and juveniles, $N$ $867=27$ ); differentiated femoral scales (generation glands) in males 13-38 per thigh $(N=10)$; 868 lamellae under fourth toe 15-20.

869 For the seven specimens examined by D.G. Broadley (see below): occipitals 6; dorsal scale rows 870 transversely 34-38, longitudinally 22-24 (26 in NMZB-UM 1542); femoral pores/thigh 9-13.

871

872 Colour: (Figs 2, 15B) Back usually sandy brown with irregular, black-bordered, cream or white 873 blotches (ocelli) forming 5-6 (seven in NMB R10911) slightly to greatly interrupted transverse 874 bands between the legs that continue onto the tail, together with a band immediately behind the 875 occipitals and another on the nape $(N=16)$. This colour pattern is often evident in live (e.g. Fig. $87615 B$ ) and preserved specimens (Fig. 2, specimens preserved for over 30 years). Ocelli may be in 
877 close proximity and even set within a continuous black band. Occasional specimens have grey-

878 brown backs with small, widely separated white spots lacking obvious black-borders (e.g. fig.

879212 in Reissig, 2014). All six NMB specimens from Manyiseni region in KwaZulu-Natal

880 (preserved for over 12 years) have medium brown backs and the pale markings have only

881 moderately distinct borders. Belly white to cream, usually with numerous small, square,

882 rectangular or irregular pale to dark brown markings; occasionally mostly without markings

883 except for the sides (e.g. NMB R10898 and 10912) or with a large dark blotch on each ventral

884 (NMB R9292). The flanks are mostly pale whitish, occasionally with some darker colouring and 885 pale vertical bars. Top of limbs with numerous irregular cream to yellowish spots and blotches; 886 underparts of limbs mostly cream with occasional scattered, irregular brown markings. Top of

887 head tan/khaki brown with dark brown patches and scattered, irregular, cream markings (or small 888 yellow speckles or blotches, observed in photographs of live specimens; e.g. Ping, 2019); throat 889 mostly white to cream with varying amounts of darker markings in the form of small spots and 890 blotches (often extensive and bold [e.g. TM 53869], but less so than in S. swazicus sp. nov.). 891

892 Cranial skeleton, post-cranial skeleton and dermal osteology (Fig. 14)

893 The cranial skeleton, post-cranial skeleton and osteoderms are all similar to those described for 894 S. swazicus sp. nov. However, the quadrates of $S$. warreni lack a pronounced ridge and concave 895 region at the lateral edge of the posterior origin of the adductor musculus mandibulae (quadrates 896 have a pronounced ridge and concave region in S. swazicus sp. nov.).

897

898 Size. Largest male (TM 78963, Mananga Mountain, Mpumalanga, South Africa) $127.3+193.5$

899 [on museum tag] $=320.8$ mm. Largest female (NMB R9292, Mananga Mountain) $128.9+182=$ $900311 \mathrm{~mm}$, but TM 53869 (Lomahasha, Eswatini) has SVL of $141.1 \mathrm{~mm}$ (tail broken/missing).

901

902 Natural history. Diurnal and rupicolous, occurring in crevices between or under rocks on 903 outcrops along the Lebombo mountains (Fig. 15A). According to FitzSimons' (1943), ants, 904 beetles, fossorial wasps, myriapods, frogs and lizards are eaten. Loveridge (1944) noted that for a 905 sample from Ubombo, one specimen had eaten 32 Eristalis (drone fly) maggots, another lizard 906 contained millipedes and ants, while a third had consumed a large grasshopper. Females give 907 birth to 4-5 young in late summer (FitzSimons, 1943). 
908

909 Distribution. Endemic to the Lebombo Mountains of eastern Eswatini, adjacent western

910 Mozambique and South Africa (north-eastern Mpumalanga and north-eastern KwaZulu-Natal)

911 (Fig. 9) at elevations of 82 to $745 \mathrm{~m}$ a.s.1.

912

913 Localities. (*specimens examined by D.G. Broadley - not included in morphological analysis,

914 but scalation data noted above) MOZAMBIQUE: Estatuene (26²4'18’'S, 3204'42” E) NMZB-

915 UM 30510-3*; Meponduine (2556’45”S, 3158’44”E) NMZB 30514*, 30562*; near Moambo

916 close to Komati River (25³5'23’S, 32¹4'47’E; photo: L. Verburgt [pers. comm.], in Reissig,

917 2014: 188, fig. 213). SOUTH AFRICA: KwaZulu-Natal Province. Bhokweni (27²2’S, 3203'E)

918 TM 78969-72, 78974; Ingwavuma (270'ㅇ, 3201'E) TM 15319-20; Manyiseni region

919 (2654'52’S, 3200’31'E) NMB R10878, 10898, 10910-3; Farm: Middlein 84 (27²1'03.0' 'S,

920 31 '59'10.7''E; photographic record: S. Nielsen); Ubombo (27³4’S, 3205'E) TM 582, 2808,

921 13639-41; NMZB-UM 1542*. Mpumalanga. Duikerhoek 489JU (2542’S, 3157’E) TM 78966;

922 Halfkroon Spruit, Kruger National Park (2531BD) TM 78973, ‘J6955’; Mananga Mountain

923 (2558'S, 31 $\left.{ }^{\circ} 52^{\prime} \mathrm{E}\right)$ TM 78961-5; Mananga Mountain, 2 km SSW of Nsizwane (2554'12’'S,

924 3152'12’E) NMB R9197-200, 9292; The Hippos 192JU (25²8’00’S, 3157’30”E) TM

925 78967-8. ESWATINI: Lomahasha (2559’S, 3159’E) TM 50130-1, 53869, 63567; Lubombo

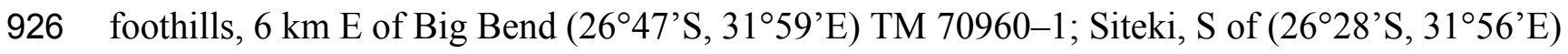

927 TM 47449; Tshaneni (2559’S, 3146’E) TM 50660-1. NO DATA: AMNH 173381 (used for

928 CT scanning).

929

930 Notes. Boulenger's (1908) description was based on two male specimens (i.e. syntypes) from

931 Ubombo in the Lebombo Mountains of KwaZulu-Natal. His description includes a plate with a

932 splendid drawing (by A.H. Searle) depicting a specimen with somewhat indistinct, narrow, dark

933 crossbars on the back, each containing scattered pale spots. This illustration, together with

934 Boulenger's (1908: 233) description: "Dark brown above, with small yellow black-edged spots

935 forming more or less regular transverse series on the body; lower parts pale brown”, characterise

936 S. warreni (but back usually light brown, see Fig. 15). Reissig (2014) noted that the 'type

937 specimen' is NHM 1946.8.8.1. 
939

940

941

942

943

944

945

946

947

948

949

950

951

952

953

954

955

956

957

958

959

960

961

962

963

964

965

966

967

\section{A revised diagnostic key to the genus Smaug}

1a. Occipitals greatly enlarged, the outer ones strongly spinose and about twice as long as those of the median pair; dorsal scales strongly spinose; ventral scales imbricate; lamellae under fourth toe $10-12$ S. giganteus

1b. Occipitals moderately to weakly enlarged, those of the outer pair somewhat larger or of similar size to the others; dorsal scales not strongly spinose; ventral scales non-imbricate; lamellae under fourth toe 14-20 2

2a. Occipitals of the outermost pair largest (and longest), innermost the smallest (and shortest).

$2 \mathrm{~b}$. Occipitals of the outermost pair not the largest (or longest), innermost of similar size to other occipitals or slightly smaller (and shorter)

3a. Dorsum mostly plain brown, at most with occasional scattered pale markings; belly cream or brown; throat plain or with small brown spots; ventrals in 10-14 rows longitudinally

3b. Dorsum brown with transversely enlarged cream markings, at least at the sides of the back, but often extensively on the back and tail; belly dark with short pale transverse markings, especially towards the edges; throat pale with dark reticulations; ventrals in 12-16 rows longitudinally S. vandami

4a. Back with few or no pale markings; flanks mostly plain, and brightly coloured (red, orange or yellow) in males; first supralabial with distinct upward prolongation; dorsals in 22-30 rows longitudinally 5

4b. Back usually with distinct pale markings (except the 'laevigata' form of S. depressus); flanks of males with light and dark markings, and not brightly coloured; first supralabial with moderate or no upward prolongation; dorsals in 13-28 rows longitudinally 
968 5a. Loreal large and not elongated, separated from nostril by upward prolongation of first

969

970

971

972

973

974

975

976

977

978

979

980

981

982

983

984

985

986

987

988

989

990

991

992

993

994

995

996

997

998 supralabial; preocular usually widely separated from the nasal by the loreal; throat of male uniform dark brown S. mossambicus

5b. Loreal small and elongated, in contact with nostril; preocular large and usually in contact (or nearly so) with the nasal above the loreal; throat of male yellow or orange, with dark infuscations S. regius

6a. Back usually with distinct, small to moderate, scattered white spots or irregular markings, not forming crossbands, or completely plain grey ('laevigata' form); dorsals in 13-21 rows longitudinally; differentiated femoral scales (generation glands) in males 14-16

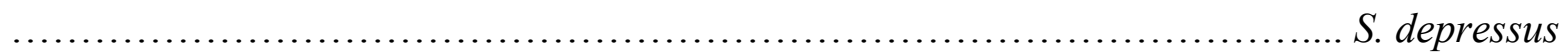

6b. Back with distinct crossbands (usually interrupted) consisting of cream spots, blotches or transversely enlarged bars, often with dark edges; dorsals in 18-28 rows longitudinally; differentiated femoral scales (generation glands) in males 19-38

7a. Outer occipital of similar length to the occipital adjacent to it; small occipital often present between median pair; back medium to light brown with distinctly dark-edged pale spots or blotches forming crossbands; belly usually with centre of each scale brown (not mostly black or brown, or with brown crossbars interrupted by a median band); throat with small brown spots S. warreni

7b. Outer occipital usually shorter than the occipital adjacent to it; small occipital seldom present between median pair; back dark brown to black with pale markings, mostly in the form of narrow, transversely enlarged bars; throat black or with dark reticulations ...... 8

8a. Back with 4-5 pale crossbands between the fore-and hindlimbs, with a pale spot on the nape behind the occipitals; throat mostly black; flanks dark with narrow, pale, vertical bars; belly mostly black, with a few pale markings at the sides; scales at anterior edges of ear openings elongated and spinose; dorsals in 28-34 (mostly $\leq 32$ ) rows transversely

8 b. Back usually with 5-6 pale crossbands between the fore-and hindlimbs, with a pale band on the nape behind the occipitals; throat pale with dark reticulations; flanks with large cream 
999

1000

1001

1002

1003

1004

1005

1006

1007

1008

1009

1010

1011

1012

1013

1014

1015

1016

1017

1018

1019

1020

1021

1022

1023

1024

1025

1026

1027

1028

1029

spots and blotches; belly with brown crossbars interrupted by a dark median band; scales at anterior edges of ear openings short and blunt; dorsals in 31-41 (mostly $\geq 32$ ) rows transversely S. swazicus sp. nov.

\section{DISCUSSION}

Examination of voucher specimens (NMB) used for the molecular analysis of Stanley \& Bates (2014), as well as most other available museum material of the three lineages, indicated that the 'Eswatini' lineage - including populations in a small area on the northern Eswatini-Mpumalanga border, and northern KwaZulu-Natal Province in South Africa—was readily distinguishable from $S$. barbertonensis sensu stricto (and $S$. warreni) by its unique dorsal, lateral and ventral colour patterns. FitzSimons (1943) had in fact noted differences in colour pattern between specimens of $S$. barbertonensis from the type locality of Barberton and specimens from 'HlutiGoedgegun' in Eswatini (now referred to the new species), but this had been regarded as merely representing regional variation.

Multivariate analyses of scale counts and body dimensions indicates that the 'Eswatini' lineage and $S$. warreni are most similar. In particular, $S$. barbertonensis differed from the other two lineages by its generally greater numbers of transverse rows of dorsal scales, more spinose scales at the anterior edges of the ear openings, and a relatively wider head. Also, the outer and adjacent inner occipital scales in S. warreni are of similar length, distinguishing it from the other two species which have the outer occipital usually slightly shorter that the adjacent inner occipital. High resolution Computed Tomography reveals differences in cranial osteology between specimens from all three lineages, with the 'Eswatini' lineage being remarkable in having a pronounced ridge and concave region at the lateral edge of the posterior origin of the adductor musculus mandibulae.

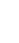

The 'Eswatini' lineage is described here as a new species, Smaug swazicus sp. nov., on the basis of genetic distinctiveness and diagnostic scalation and colour patterns. It appears to have a fairly widespread distribution in Eswatini west of the Lebombo Mountains, and a 
1030 somewhat peripheral distribution in South Africa near its borders with Mpumalanga and

1031 KwaZulu-Natal provinces. We estimate that about $90 \%$ of its range is in Eswatini and suggest 1032 that it be considered near-endemic to that country. Recognition of the new species means that $S$.

1033 barbertonensis sensu stricto is a South African endemic restricted to an altitudinal band of about $1034300 \mathrm{~m}$ in the Barberton-Nelspruit-Khandizwe area of eastern Mpumalanga Province, while $S$. 1035 warreni is endemic to the narrow Lebombo Mountain range of South Africa, Eswatini and 1036 Mozambique.

1037 1038 1039

The phylogenetic analysis of Stanley \& Bates (2014) did not include samples from the southern part of the range (especially KwaZulu-Natal) of S. swazicus sp. nov., but northern (including one locality in Mpumalanga) and southern material is morphologically indistinguishable, and so we provisionally treat all these populations as S. swazicus sp. nov. 1042

The geographical break between $S$. barbertonensis and $S$. swazicus appears to correspond 1044 to the location of the ancient Makhonjwa mountain range, which lies directly south of Barberton. This range, also referred to as the Barberton Greenstone belt, is made up of some of the world's oldest exposed rocks (3.6 billion years old) which contain fossilised evidence of the earliest life on Earth (De Wit, 2010). The time-calibrated phylogenetic analyses of the $S$. warreni species complex by Stanley \& Bates (2014) indicates that the $S$. warreni-S. swazicus sp. nov. lineage diverged from $S$. barbertonensis during the late Miocene, around 7.5 million years ago. This is somewhat earlier than the most recent and extreme period of uplift of the eastern escarpment (Partridge \& Maud, 1987), suggesting that populations on either side of the Makhonjwa mountains were isolated before that time. The population east of the Makhonjwa mountains split around 6.2 million years ago (Stanley \& Bates, 2014), after which time $S$. warreni became closely associated with the narrow Lebombo mountain range. approximated by the southern-most taxa of rupicolous flat lizards in the Platysaurus intermedius A. Smith, 1844 species group (see Scott et al., 2004; Bates et al., 2014): the range of P. $i$. wilhelmi Hewitt, 1909 approximates that of S. barbertonensis (although the former also occurs further north), that of $P$. $i$. natalensis FitzSimons, 1948 is similar to $S$. swazicus sp. nov., and $P$. 
1061 lebomboensis Jacobsen, 1994 is, like, S. warreni, restricted to the Lebombo mountain range (Fig.

1062 8). A taxonomically comprehensive phylogenetic analysis of Platysaurus that will clarify

1063 relationships and make further geographic comparisons possible is in preparation (S. Keogh pers.

1064 comm.). In the Afroedura multiporus (Hewitt, 1925) group of rupicolous flat geckos (see

1065 Jacobsen et al., 2014; Bates et al., 2014), A. haackei (Onderstall, 1984) has a similar distribution

1066 to S. barbertonensis, and appears to be separated from A. major (Onderstall, 1984) in north-

1067 western Eswatini by the Makhonjwa range, as are S. barbertonensis and S. swazicus sp. nov.

1068 (Fig. 8). In the thread snake genus Leptotyphlops Fitzinger, 1843, L. telloi Broadley \& Watson,

10691976 is also endemic to the Lebombos (Bates et al., 2014).

1070

1071 Conservation implications

1072 Due to their obligate rupicolous ecology, members of the Smang warreni species complex are

1073 not subject to the same levels of habitat destruction as their terrestrial congener, S. giganteus.

1074 Jacobsen (1989) listed all species of Smaug (except the Vulnerable S. giganteus) as protected

1075 schedule 2 (Transvaal Nature Conservation Ordinance 12 of 1983), while Bates et al. (2014) and

1076 Bates \& Mouton (2018a) reported their global conservation status as "Least Concern", while

1077 recommending that further research is needed to assess the impact of tree removal from the

1078 habitat of S. barbertonensis (i.e. S. barbertonensis and S. swazicus sp. nov.) as crevices in the

1079 partial shade of trees are often selected for shelter (Jacobsen, 1989). In this regard Richard C.

1080 Boycott (2019, in litt.) noted that when he visited the locality 'between Hluti and Goedgegun' in

1081 Eswatini (as reported by FitzSimons, 1943) a few years ago, S. swazicus sp. nov. was not

1082 present, possibly because all large trees along the rocky hillsides had disappeared, such that

1083 dappled shade was no longer available. The species appeared to have been replaced by skinks

1084 (Trachylepis varia [Peters, 1867] and T. margaritifer [Peters, 1854]). Part of the natural range of

1085 S. swazicus sp. nov. was inundated and thus lost to the species when the Maguga Dam in

1086 Eswatini was filled in 2002/3, although about 20 specimens were collected by Boycott and

1087 relocated downstream from the Dam as part of the Maguga Dam Comprehensive Mitigation Plan

1088 (R C Boycott, 2019, in litt.). The recognition of $S$. swazicus sp. nov. means that the range of $S$.

1089 barbertonensis sensu stricto now covers only about $180 \mathrm{~km}^{2}$. Also, this species has been

1090 recorded within a narrow altitudinal band of only $300 \mathrm{~m}$. Its conservation status should therefore

1091 be monitored. Despite being endemic to the narrow Lebombo mountain range, $S$. warreni

Peer] reviewing PDF | (2019:08:40394:2:0:CHECK 24 Dec 2019) 
1092 apparently does not face any significant threats, and it is therefore also considered "Least 1093 Concern" (Bates et al., 2014; Bates \& Mouton, 2018a). It appears to occur throughout the 1094 Lebombo range, from low to high altitudes (82 to $745 \mathrm{~m}$ a.s.1.). Using $\operatorname{IUCN}(2012,2017)$ 1095 criteria, we suggest that all three species be regarded as Least Concern at this time.

1097 CONCLUSIONS

1098 Following the finding by Stanley \& Bates (2014) that the south-eastern assemblage of

1099 populations referable to the $S$. warreni species complex comprised three distinct genetic lineages, 1100 we hypothesised that morphological differences should also exist between specimens referable to 1101 these lineages. Distinct differences were indeed identified between populations with regard to 1102 colour pattern, scalation and cranial osteology, necessitating the description of a new species, $S$. 1103 swazicus sp. nov., which appears to be near-endemic to Eswatini. This finding means that $S$. 1104 barbertonensis sensu stricto is endemic to South Africa, with a restricted range that may require 1105 monitoring in future to ensure that the species does not become threatened with extinction. Also, 1106 sampling of populations referable to S. swazicus sp. nov. in South Africa's KwaZulu-Natal 1107 Province is needed to investigate whether additional cryptic diversity exists in this species 1108 complex. Smaug warreni is endemic to the Lebombo range in South Africa, Eswatini and 1109 Mozambique. There are now nine known species of dragon lizards (Smaug).

\section{ACKNOWLEDGEMENTS}

1112 We thank Lauretta Mahlangu (Ditsong Natural History Museum, Pretoria) for access to, and for 1113 loans of, Smaug material in her care; the late Donald Broadley for data on specimens in the 1114 collection of the Natural History Museum of Zimbabwe (Bulawayo); Richard Boycott for 1115 information about the distribution of this genus in Eswatini; and T. Busschau for the use of his 1116 photographs of $S$. barbertonensis and its habitat.

\section{REFERENCES}

Adolphs K. 1996. Bibliographie der Gürtelechsen und Schildechsen (Reptilia: Sauria: Cordylidae \& Gerrhosauridae). Sankt Augustin: Squamata Verlag.. 
1122

1123

1124

1125

1126

1127

1128

1129

1130

1131

1132

1133

1134

1135

1136

1137

1138

1139

1140

1141

1142

1143

1144

1145

1146

1147

1148

1149

1150

1151

Adolphs K. 2006. Bibliotheca Cordyliformium. Sankt Augustin: Squamata Verlag..

Alexander G, Marais J. 2007. A guide to the reptiles of southern Africa. Cape Town: Struik Publishers.

Bates MF, Branch WR, Bauer AM, Burger M, Marais J, Alexander GJ, De Villiers MS eds. 2014. Atlas and Red List of the Reptiles of South Africa, Lesotho and Swaziland. Suricata 1. Pretoria: South African National Biodiversity Institute.

Bates MF, Mouton PLFN. 2018a. Smaug barbertonensis. The IUCN Red List of Threatened Species 2018: e.T110167262A115679786. http://dx.doi.org/10.2305/IUCN.UK.20182.RLTS.T110167262A115679786.en. Downloaded: 2 January 2019.

Bates MF, Mouton, PLFN. 2018b. Smaug warreni. The IUCN Red List of Threatened Species 2018: e.T110167218A115679533. http://dx.doi.org/10.2305/IUCN.UK.20182.RLTS.T110167218A115679533.en. Downloaded: 2 January 2019.

Boulenger GA. 1908. On a collection of fresh-water fishes, batrachians, and reptiles from Natal and Zululand, with description of new species. Annals of the Natal Government Museum (Pietermaritzburg) 1:219-235.

Boulenger GA. 1910. A Revised List of the South African Reptiles and Batrachians, with Synoptic Tables, special reference to the specimens in the South African Museum, and Descriptions of New Species. Annals of the South African Museum (Cape Town) 5(9):455538.

Bourquin O. 2004. Reptiles (Reptilia) in KwaZulu-Natal: I - diversity and distribution. Durban Museum Novitates 29:57-103. 
1152 Branch W R. 1988. Field guide to snakes and other reptiles of southern Africa. Cape Town: $1153 \quad$ Struik Publishers.

1154

1155

1156

1157

1158

1159

1160

1161

1162

1163

1164

1165

1166

1167

1168

1169

1170

1171

1172

1173

1174

1175

1176

1177

1178

1179

1180 1181

Branch W R. 1998. Field guide to snakes and other reptiles of southern Africa. Third edition. Cape Town: Struik Publishers.

Broadley D G. 1962. On some reptile collections from the North-Western and North-Eastern Districts of Southern Rhodesia 1958-61, with descriptions of four new lizards. Occasional Papers of the National Museums of Southern Rhodesia 3:787-843.

Broadley D G. 1966. The herpetology of south-east Africa. Ph.D. Thesis, University of Natal, Pietermaritzburg.

Broadley D G. 2006. CITES Standard Reference for the Species of Cordylus (Cordylidae, Reptilia): CITES Nomenclature Committee for the 14th meeting of the CoP. 10.

De Quieroz K. 1998. The General Lineage Concept of Species, Species Criteria, and the Process of Speciation. A Conceptual Unification and Terminological Recommendations. In: Howard DJ, Berlocher SH eds. Endless forms: species and speciation. Oxford: Oxford University Press, 55-75..

De Quieroz K. 2007. Species Concepts and Species Delimitation. Systematic Biology 56(6):879-886.

De Wit M J. 2010. The deep-time treasure chest of the Makhonjwa mountains. South African Journal of Science 106(5/6):1-2.

De Waal SWP. 1978. The Squamata (Reptilia) of the Orange Free State, South Africa. Memoires van die Nasionale Museum, Bloemfontein 11:i-iii, 1-160. 
1182 Fitzsimons V. 1930. Descriptions of new South African Reptilia and Batrachia, with distribution

1183

1184

1185

1186

1187

1188

1189

1190

1191

1192

1193

1194

1195

1196

1197

1198

1199

1200

1201

1202

1203

1204

1205

1206

1207

1208

1209

1210

1211 records of allied species in the Transvaal Museum Collection. Annals of the Transvaal Museum (Pretoria) 14:20-48.

Fitzsimons V. 1933. Descriptions of five new lizards from the Transvaal and Southern Rhodesia. Annals of the Transvaal Museum (Pretoria) 15:273-280.

Fitzsimons V. 1943. The lizards of South Africa. Memoirs of the Transvaal Museum (Pretoria) 1:1-528.

Fitzsimons V. 1958. A new Cordylus from Gorongoza, Mocambique. Annals of the Natal Museum (Pietermaritzburg) 14:351-353.

Frost D R, Hillis DM. 1990. Species in concept and practice: Herpetological applications. Herpetologica 46(1):87-104.

Hewitt J. 1909. Description of a New Species of Platysaurus and Notes on the Specific Characters of certain Species of Zonuridae, together with Synoptical Keys to all the known South African Species, and a résumé of our knowledge of their Distribution; and a Key to the known Genera of South African Lizards. Annals of the Transvaal Museum (Pretoria) 2(1):29-40, 1 plt.

IUCN [International Union for Conservation of Nature]. 2012. IUCN Red List Categories and Criteria: Version 3.1. Second edition. IUCN, Gland, Switzerland and Cambridge, UK.

\section{IUCN [International Union for Conservation of Nature] [Standards and Petitions}

Subcommittee]. 2017. Guidelines for Using the IUCN Red List Categories and Criteria.

Version 13. Prepared by the Standards and Petitions Subcommittee. (Downloadable from: http://www.iucnredlist.org/documents/RedListGuidelines.pdf.) 
1212 Jacobsen NHG. 1989. A herpetological survey of the Transvaal. Ph.D. Thesis, University of 1213 Natal.

1214

1215 Jacobsen NHG, Kuhn AL, Jackman TR, Bauer AM. 2014. A phylogenetic analysis of the

1216

1217

1218

1219

1220

1221

1222

1223

1224

1225

1226

1227

1228

1229

1230

1231

1232

1233

1234

1235

1236

1237

1238

1239

1240

1241

1242 southern African gecko genus Afroedura Loveridge (Squamata: Gekkonidae), with the description of nine new species from Limpopo and Mpumalanga provinces of South Africa. Zootaxa 3846(4):451-501.

Lawrence RF. 1937. The Girdle Tailed Lizard and its Mites. The Cape Naturalist 1(4):107-113.

Loveridge A. 1944. Revision of the African lizards of the family Cordylidae. Bulletin of the Museum of Comparative Zoology (Harvard College) 95(1):1-118, 12 pls.

Marques MP, Ceriaco LMP, Stanley EL, Bandeira SA, Agarwal I, Bauer AM. 2019. A new species of Girdled Lizard (Squamata: Cordylidae) from the Serra da Neve Inselberg, Namibe Province, southwestern Angola. Zootaxa 4668(4):503-524.

Mouton PIFN, Flemming A, Bates MF, Broeckhuizen C. 2018. The relationship between generation gland morphology and armour in Dragon Lizards (Smaug): A reassessment of ancestral states for the Cordylidae. Amphibia-Reptilia 39:457-470.

Parera SJ, Ratnayake-Parera D, Procheş Ş. 2011. Vertebrate distributions indicate a greater Maputaland-Pondoland-Albany region of endemism. South African Journal of Science 107(7,8), Art. \#462, 15 pages. doi:10.4102/sajs.v107i7/8.462.

Partridge RR, Maud TC. 1987. Geomorphic evolution of southern Africa since the Mesozoic. South African Journal of Geology 90(2):179-208.

Ping T. 2019. Smaug warreni warreni. Available at http://www.tyroneping.co.za/lizards/smaugwarreni-warreni/ (accessioned 7 November 2019). 
1243 Power JH. 1930. On the South African Species of the genus Zonurus. Annals of the Transvaal

1244

1245

1246

1247

1248

1249

1250

1251

1252

1253

1254

1255

1256

1257

1258

1259

1260

1261

1262

1263

1264

1265

1266

1267

1268

1269

1270

1271

1272

Museum (Pretoria) 14(1):11-19, 2 pls.

Reissig J. 2014. Girdled Lizards and their relatives: Natural History, Captive Care and Breeding. Frankfurt am Main: Edition Chimaira.

Scott IAW, Keogh JS, Whiting M. 2004. Shifting sands and shifty lizards: molecular phylogeny and biogeography of African flat lizards (Platysaurus). Molecular Phylogenetics and Evolution 31: 618-629.

Smith A. 1844. Illustrations of the Zoology of South Africa. Consisting chiefly of figures and descriptions of the objects of natural history collected during an expedition into the interior of South Africa, in the years 1834, 1835, and 1836. Fitted out by 'The Cape of Good Hope Association for Exploring Central Africa'. London: Smith, Edler and Co.

Stanley EL, Bates MF. 2014. Here be dragons: a phylogenetic and biogeographical study of the Smaug warreni species complex (Squamata: Cordylidae) in southern Africa. Zoological Journal of the Linnean Society 172:892-909.

Stanley EL, Bauer AM, Jackman, TR, Branch WR, Mouton PLFN. 2011. Between a rock and a hard polytomy: rapid radiation in the rupicolous girdled lizards (Squamata: Cordylidae). Molecular Phylogenetics and Evolution 58:53-70.

Stanley EL, Ceriaco LMP, Bandeira S, Valerio H, Bates MF, Branch WR. 2016. A review of Cordylus machadoi (Squamata: Cordylidae) in southwestern Angola, with the description of a new species from the Pro-Namib desert. Zootaxa 4061(3):201-226.

Uetz P, Freed, P, Hosek. J eds. 2019. The Reptile Database. Available at http://www.reptiledatabase.org (accessed 13 November 2019). 
1273 Van Dam G. 1921. Descriptions of new species of Zonurus, and notes on the species of Zonurus

1274 occurring in the Transvaal. Annals of the Transvaal Museum (Pretoria) 7:239-243.

1275

1276 Whiting MJ, Branch WR, Pepper M, Keogh JS. 2015. A new species of spectacularly

1277 coloured flat lizard Platysaurus (Squamata: Cordylidae: Platysaurinae) from southern

1278 Africa. Zootaxa 3986(2):173-192.

1279 


\section{Table $\mathbf{1}$ (on next page)}

Comparison of scalation data in the three species of the Smaug warreni species complex. Data for $S$. cf. barbertonensis is based on all type and additional material.

For ventral scale rows longitudinally, rare exceptions are indicated in parentheses, and superscripts indicate the relevant numbers of specimens. Femoral pores (males and females $>95 \mathrm{~mm}$ SVL only) and differentiated femoral scales (generation glands, males >95 mm SVL only) are expressed as average number per thigh (left and right sides examined). 
1

2 Table 1. Comparison of scalation data in the three species of the Smaug warreni complex. Data

3 for $S$. cf. barbertonensis is based on all type and additional material. For ventral scale rows

4 longitudinally, rare exceptions are indicated in parentheses, and superscripts indicate the relevant

5 numbers of specimens. Femoral pores (males and females $>95 \mathrm{~mm}$ SVL only) and differentiated

6 femoral scales (generation glands, males $>95 \mathrm{~mm}$ SVL only) are expressed as average number per

7 thigh (left and right sides examined).

8

\begin{tabular}{|c|c|c|c|c|c|c|c|c|}
\hline & 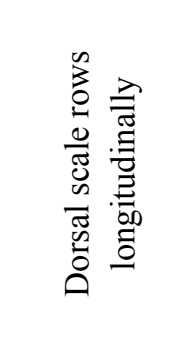 & 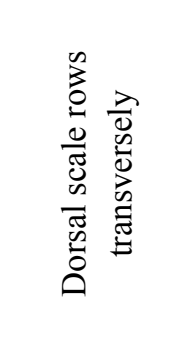 & 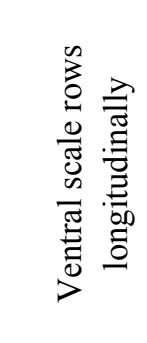 & 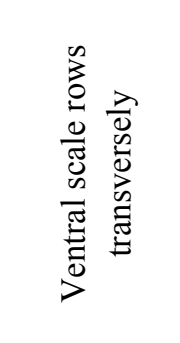 & 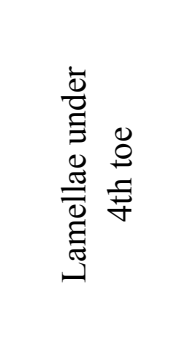 & 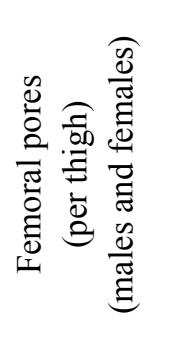 & 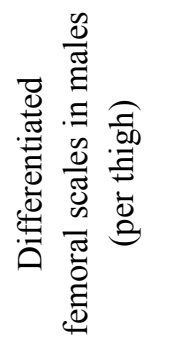 & 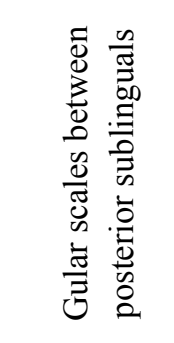 \\
\hline Smaug & $20-26$ & $31-41$ & 14 & $23-29$ & $16-19$ & $10-13$ & $9.5-33$ & $22-29$ \\
\hline \multirow[t]{2}{*}{ cf. barbertonensis } & $22.6 \pm 1.53$ & $34.7 \pm 2.37$ & $\left(12^{2}\right)$ & $26.3 \pm 1.24$ & $17.6 \pm 0.85$ & $11.2 \pm 0.90$ & $23.2 \pm 7.25$ & $25.7 \pm 1.93$ \\
\hline & $N=22$ & $N=22$ & & $N=21$ & $N=22$ & $N=17$ & $N=9$ & $N=20$ \\
\hline Smaug & $20-24$ & $28-34$ & 14 & $25-28$ & $15-19$ & $8.5-11.5$ & $18.5-35.5$ & (20) $23-31$ \\
\hline \multirow[t]{2}{*}{ barbertonensis } & $21.7 \pm 1.46$ & $30.5 \pm 1.48$ & $\left(16^{1}\right)$ & $26.4 \pm 0.86$ & $17.7 \pm 1.04$ & $9.9 \pm 0.79$ & $25.9 \pm 5.16$ & $27.0 \pm 2.47$ \\
\hline & $N=26$ & $N=26$ & & $N=26$ & $N=26$ & $N=20$ & $N=9$ & $N=26$ \\
\hline Smaug & $22-28$ & $31-41$ & 14 & $23-27$ & $15-20$ & $7.5-13$ & $14.5-38$ & $23-32$ \\
\hline \multirow[t]{2}{*}{ warreni } & $23.6 \pm 1.42$ & $35.2 \pm 2.11$ & $\left(12^{2}, 13^{1}\right)$ & $25.9 \pm 1.00$ & $16.8 \pm 1.20$ & $10.4 \pm 1.30$ & $25.7 \pm 6.81$ & $26.8 \pm 1.94$ \\
\hline & $N=39$ & $N=39$ & & $N=39$ & $N=39$ & $N=31$ & $N=9$ & $N=37$ \\
\hline
\end{tabular}




\section{Table 2 (on next page)}

Mensural data $(\mathrm{mm})$ for the type series of Smaug swazicus sp. nov. ( $\mathrm{M}=$ male, $\mathrm{F}=$ female, $\mathrm{J}=$ juvenile; $r$ = regenerating tail). 
1

2 Table 2. Mensural data $(\mathrm{mm})$ for the type series of Smang swazicus sp. nov. $(\mathrm{M}=$ male, $\mathrm{F}=$ 3 female, $\mathrm{J}=$ juvenile; $\mathrm{r}=$ regenerating tail).

4

\begin{tabular}{|llccccccc|}
\hline $\begin{array}{l}\text { Museum } \\
\text { number }\end{array}$ & $\begin{array}{l}\text { Type } \\
\text { status }\end{array}$ & Sex & $\begin{array}{c}\text { Snout- } \\
\text { vent } \\
\text { length }\end{array}$ & $\begin{array}{c}\text { Tail } \\
\text { length }\end{array}$ & $\begin{array}{c}\text { Total } \\
\text { length }\end{array}$ & $\begin{array}{c}\text { Head } \\
\text { length }\end{array}$ & $\begin{array}{c}\text { Head } \\
\text { width }\end{array}$ & $\begin{array}{c}\text { Head } \\
\text { depth }\end{array}$ \\
\hline NMB R9201 & Holotype & M & 138.76 & 187 & 325.76 & 40.19 & 31.15 & 16.19 \\
TM 78918 & Allotype & F & 143.80 & 161 & 304.80 & 37.23 & 29.14 & 15.97 \\
TM 83000 & Paratype & M & 129.35 & 150 & 279.35 & 34.86 & 27.99 & 14.85 \\
TM 83532 & Paratype & F & 132.08 & & & 35.11 & 28.55 & 15.08 \\
TM 42531 & Paratype & F & 102.77 & & & 29.23 & 23.71 & 12.25 \\
TM 51376 & Paratype & M & 129.60 & & & 36.37 & 29.60 & 17.71 \\
TM 78931 & Paratype & J & 70.14 & & & 21.00 & 16.30 & 8.00 \\
TM 78921 & Paratype & J & 65.76 & & & 19.33 & 14.07 & 8.14 \\
NMB R9194 & Paratype & M & 139.95 & 202 & 341.95 & 40.53 & 33.51 & 17.92 \\
NMB R9195 & Paratype & M & 145.01 & & & 41.96 & 34.36 & 18.71 \\
NMB R9202 & Paratype & M & 141.23 & $140 \mathrm{r}$ & $281.23+$ & 40.11 & 32.73 & 16.61 \\
TM 73290 & Paratype & F & 140.11 & $116.40 r$ & $256.51+$ & 37.49 & 30.97 & 17.86 \\
\hline
\end{tabular}

5 


\section{Table 3(on next page)}

Meristic data for the type series of Smaug swazicus sp. nov. $(\mathrm{H}=$ holotype, $\mathrm{A}=$ allotype, $\mathrm{P}=$ paratype).

Values on either side of a slash refer to the animal's left and right sides respectively. 
Table 3. Meristic data for the type series of Smaug swazicus sp. nov. ( $\mathrm{H}=$ holotype, $\mathrm{A}=$ allotype,

$3 \mathrm{P}=$ paratype); values on either side of a slash refer to the animal's left and right sides respectively. 4

\begin{tabular}{|c|c|c|c|c|c|c|c|c|c|}
\hline $\begin{array}{l}\text { Museum } \\
\text { number }\end{array}$ & 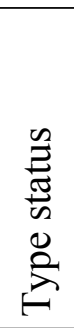 & 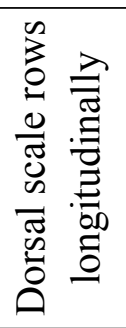 & 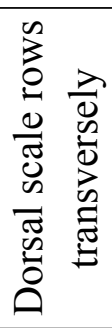 & 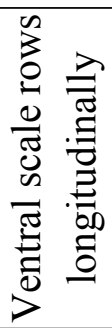 & 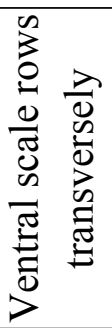 & 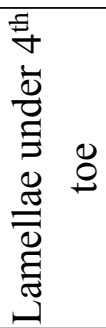 & 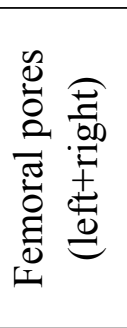 & 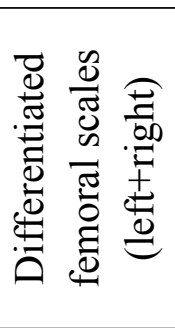 & 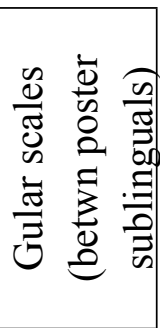 \\
\hline NMB R9201 & $\mathrm{H}$ & 20 & 34 & 14 & 26 & 16 & $10 / 11$ & $21 / 25$ & 23 \\
\hline TM 78918 & A & 21 & 34 & 14 & 28 & 18 & $10 / 10$ & $0 / 0$ & 25 \\
\hline TM 83000 & $\mathrm{P}$ & 22 & 34 & 14 & 23 & 16 & $10 / 10$ & $10 / 9$ & 28 \\
\hline TM 83532 & $\mathrm{P}$ & 25 & 41 & 14 & 29 & 18 & $11 / 10$ & $0 / 0$ & 27 \\
\hline TM 42531 & $\mathrm{P}$ & 22 & 37 & 14 & 25 & 17 & $10 / 10$ & $0 / 0$ & 28 \\
\hline TM 51376 & $\mathrm{P}$ & 26 & 36 & 12 & 26 & 18 & $? / 11$ & $? / 24$ & 26 \\
\hline TM 78931 & $\mathrm{P}$ & 21 & 35 & 14 & 26 & 17 & $12 / 12$ & $10 / 16$ & 25 \\
\hline TM 78921 & $\mathrm{P}$ & 23 & 32 & 14 & 25 & 18 & $11 / 11$ & $12 / 12$ & 24 \\
\hline NMB R9194 & $\mathrm{P}$ & 22 & 34 & 12 & 26 & 17 & $11 / 12$ & $26 / 35$ & 22 \\
\hline NMB R9195 & $\mathrm{P}$ & 25 & 35 & 14 & 27 & 17 & $12 / 11$ & $33 / ?$ & 25 \\
\hline NMB R9202 & $\mathrm{P}$ & 22 & 34 & 14 & 27 & 18 & $12 / 11$ & $15 / 19$ & 24 \\
\hline TM 73290 & $\mathrm{P}$ & 24 & 37 & 14 & 27 & 19 & $11 / 10$ & $0 / 0$ & $?$ \\
\hline
\end{tabular}

5 
Figure 1

Time calibrated phylogram of 11 concatenated nuclear and mitochondrial genes for the genus Smaug.

Bootstrap support values (MP/ML) are shown above branches, and posterior probabilities below branches. (Modified from: Stanley \& Bates 2014, fig. 4.) (Image produced by: E.L. Stanley) 


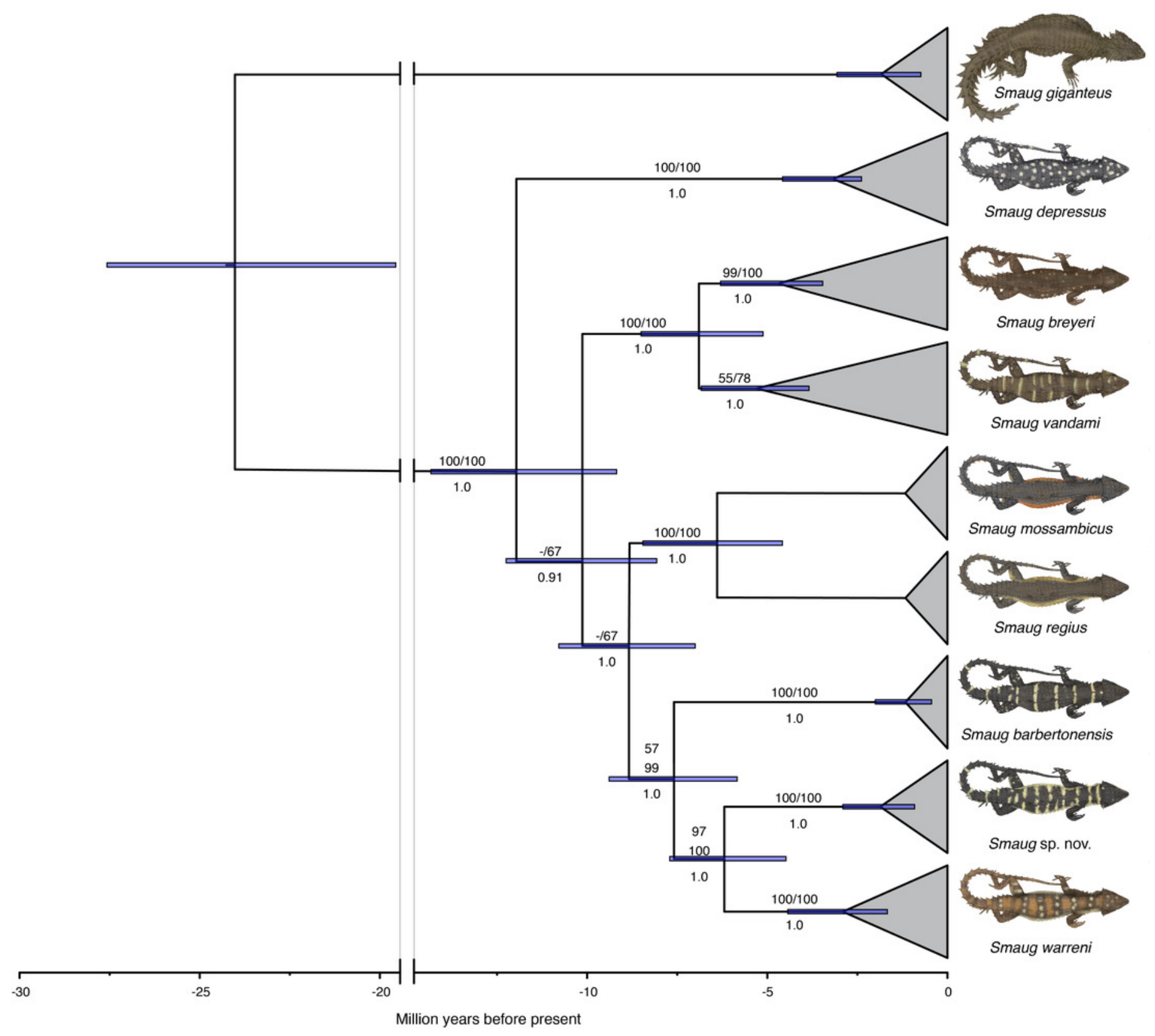


Figure 2

Differences in colour pattern in the Smaug warreni species complex.

From left to right: Dorsal views of (A) Smaug barbertonensis (NMB R9196, topotype), (B) S. cf. barbertonensis (TM 78918, allotype, see below) and (C) S. warreni (TM 63567); ventral views of (D) S. barbertonensis (TM 55789), (E) S. cf. barbertonensis (TM 78918) and (F) S. warreni (TM 78969) (Photo credits: M.F. Bates). 


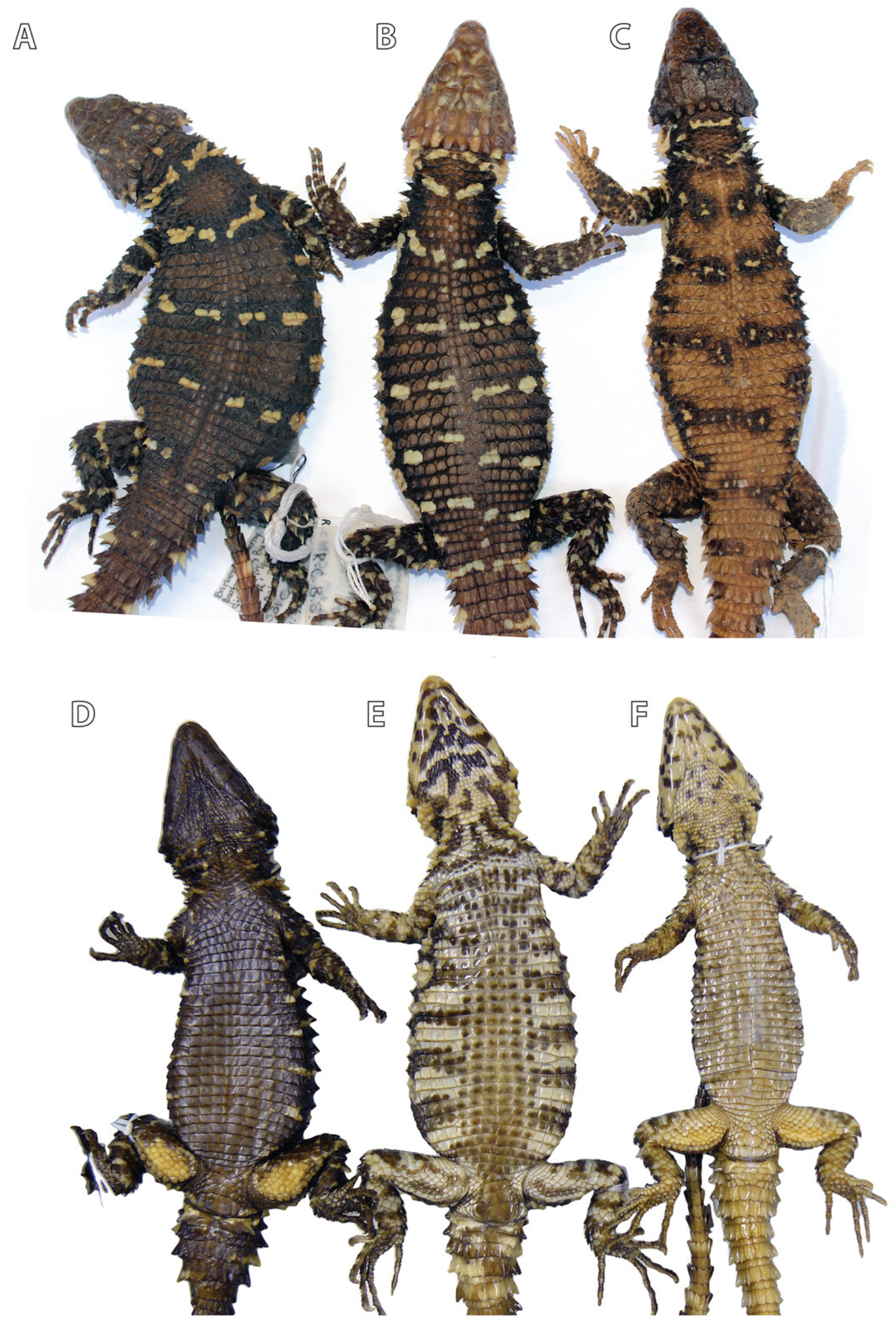




\section{Figure 3}

Quadrate variation in the Smaug warreni species complex.

(A-C) S. warreni NMB R9292. (D-F) S. warreni AMNH-R-173381. (G-I) S. cf. barbertonensis AMNH-R-173382. (J-L) S. cf. barbertonensis NMB R9201 (holotype, see below). (M-O) S. barbertonensis NMB R9196 (topotype). Diagnostic ridges on the quadrates of S. cf. barbertonensis are indicated using arrows. Horizontal bar $=5 \mathrm{~mm}$. (Images produced by: E.L. Stanley) 


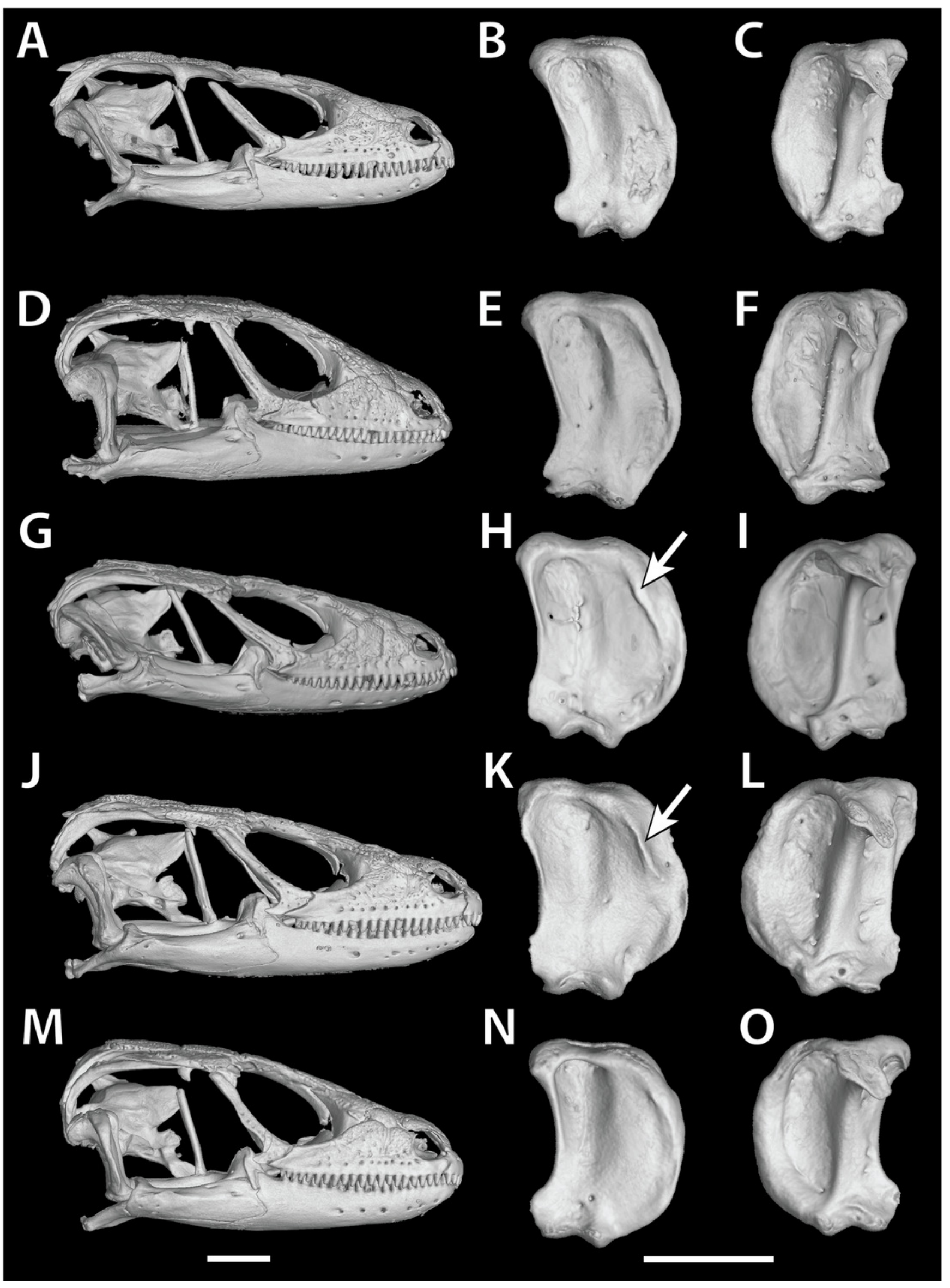

Peer) reviewing PDF | (2019:08:40394:2:0:CHECK 24 Dec 2019) 
Figure 4

Morphological variation in the Smaug warreni species complex.

(A) Bar graph showing numbers of dorsal scale rows transversely (S. warreni, $N=39$; $S$. barbertonensis, $N=$ 26; S. swazicus sp. nov., $N=22$ ). (B) Scatterplot showing head length and head width (corrected by SVL) (>70 mm SVL: S. warreni, $N=33$; S. barbertonensis, $N=21$; S. swazicus sp. nov., $N=20$. (C) Principal Component analysis of 13 meristic and three linear characters (S. warreni, $N=31$; S. barbertonensis, $N=$ 23; S. swazicus sp. nov., $N=18$ ). (D) Linear Discriminate analysis of 13 meristic and three linear characters ( $S$. warreni, $N=31 ; S$. barbertonensis, $N=23$; $S$. swazicus sp. nov., $N=18$ ). In all graphs, $S$. warreni in blue, S. barbertonensis in red, S. swazicus sp. nov. in green. (Graphs produced by: E.L. Stanley)
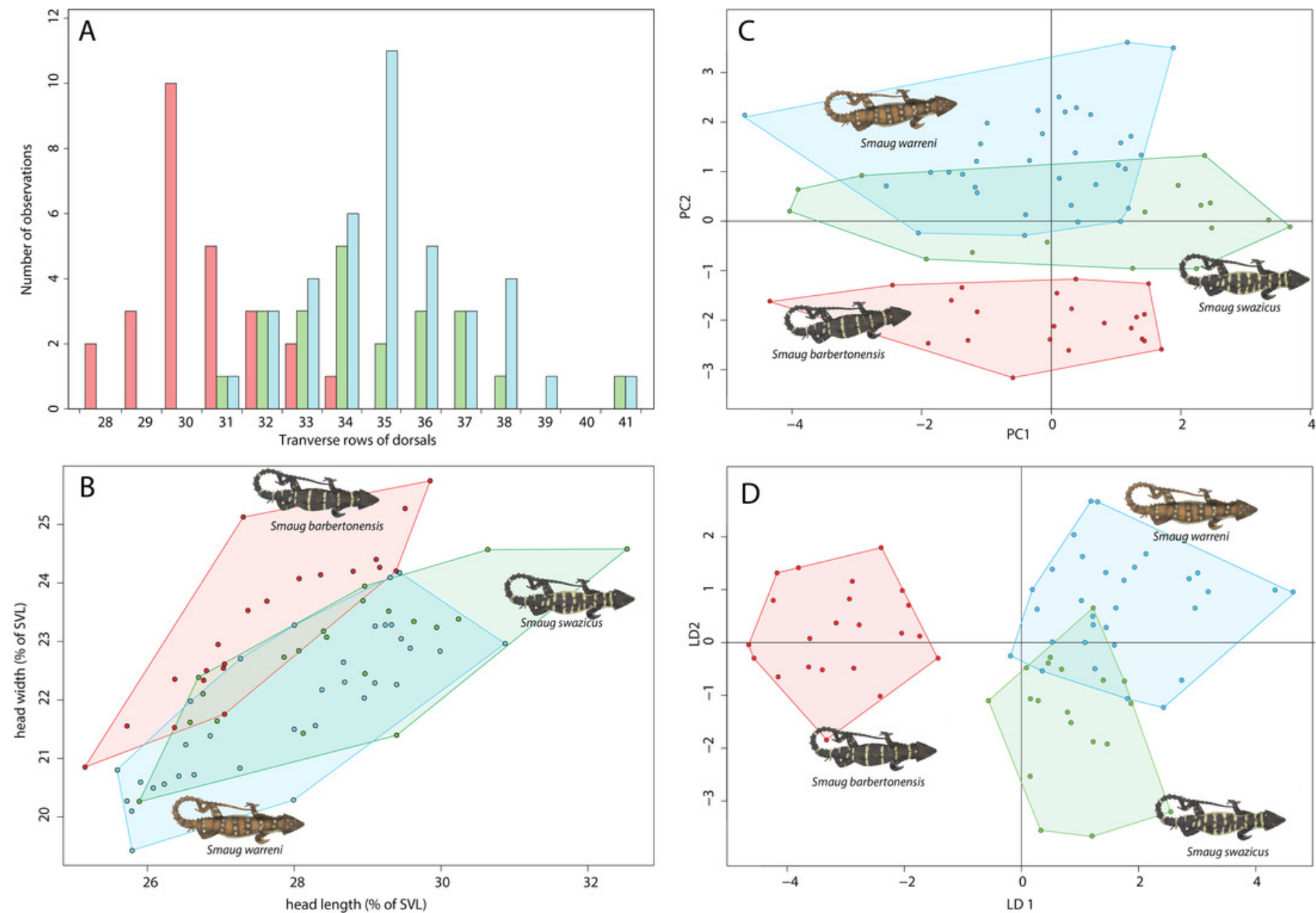
Figure 5

Smaug swazicus sp. nov. (A) Dorsal, (B) ventral and (C) lateral views of the head of the holotype (NMB R9201). (Drawing credit: E.L. Stanley)
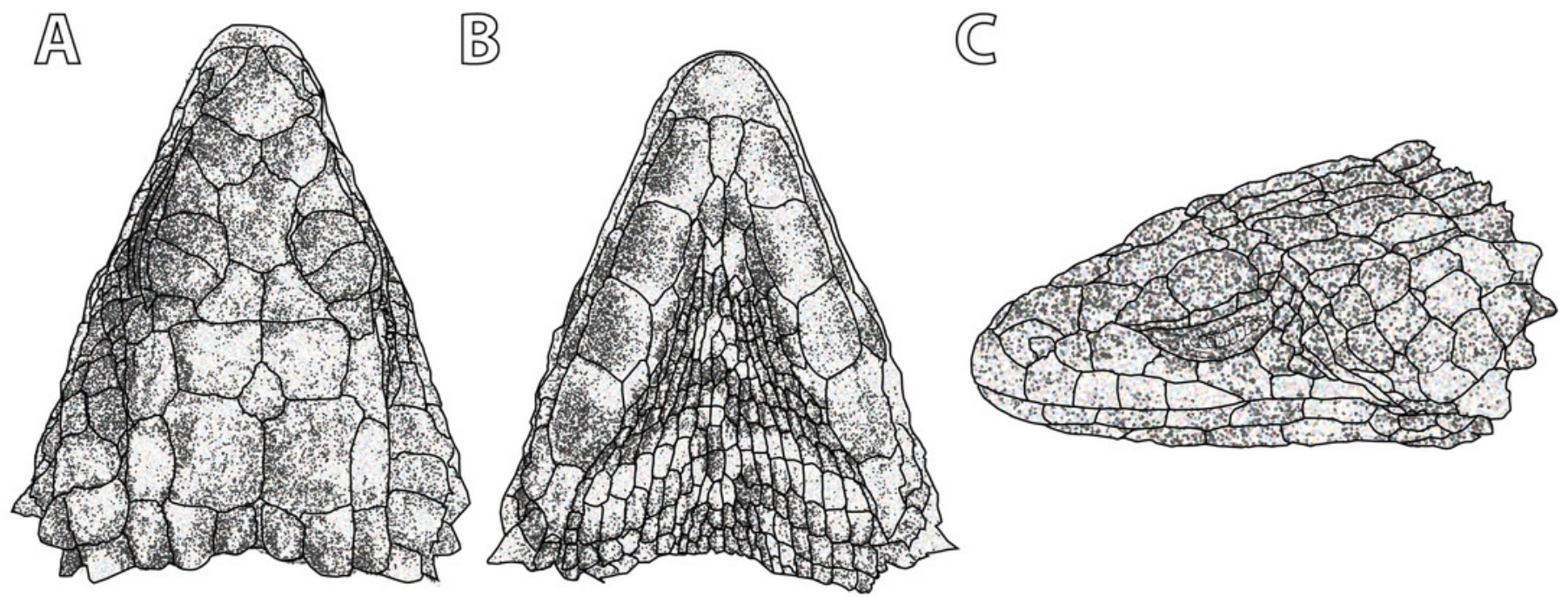
Figure 6

Smaug swazicus sp. nov. Holotype (NMB R9201).

(A) Dorsal view. (B) Ventral view. (Photo credits: M.F. Bates)
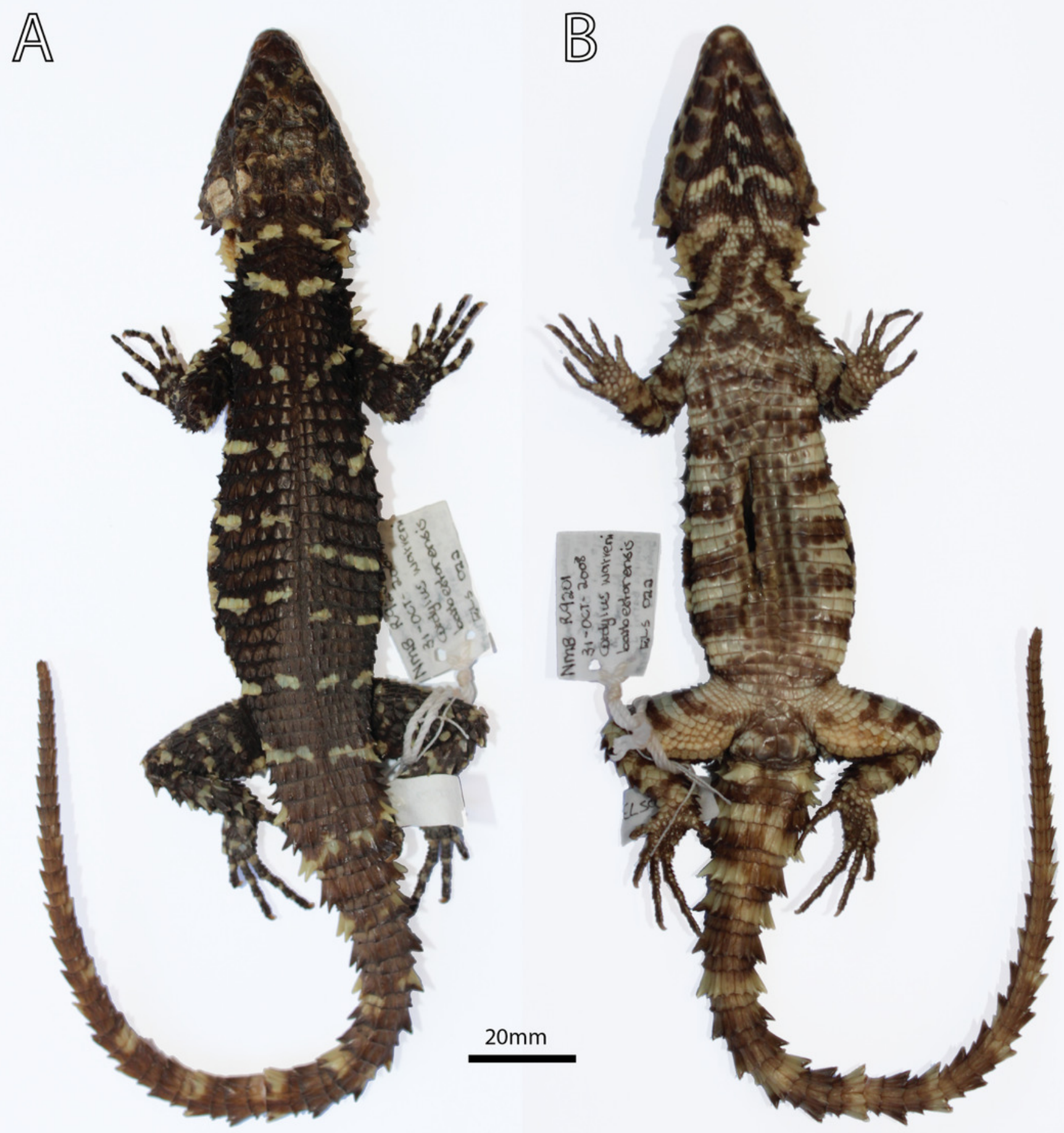


\section{Figure 7}

Cranial (A-C), postcranial (D), and dermal (E-F) osteology of Smaug swazicus sp. nov. (holotype, NMB R9201).

Body ostoderms are highlighted in blue-green. Abbreviations: An, angular; Art, articular; Bo, basioccipital; Bpt, basipterygoid; Co, coranoid; De, dentary; Ec, ectopterygoid; Ep, epipterygoid; F, frontal; J, jugal; Mx, maxilla; N, nasal; P, parietal; Pa, palatine; Pf, postfrontal; Pmx, premaxilla; Po, postorbital; Pocc, paraoccipital; Prf, prefrontal; Pt, pterygoid; Q, quadrate; Sq, squamosal; St, supratemporal; Vo, vomer. (Images produced by: E.L. Stanley)

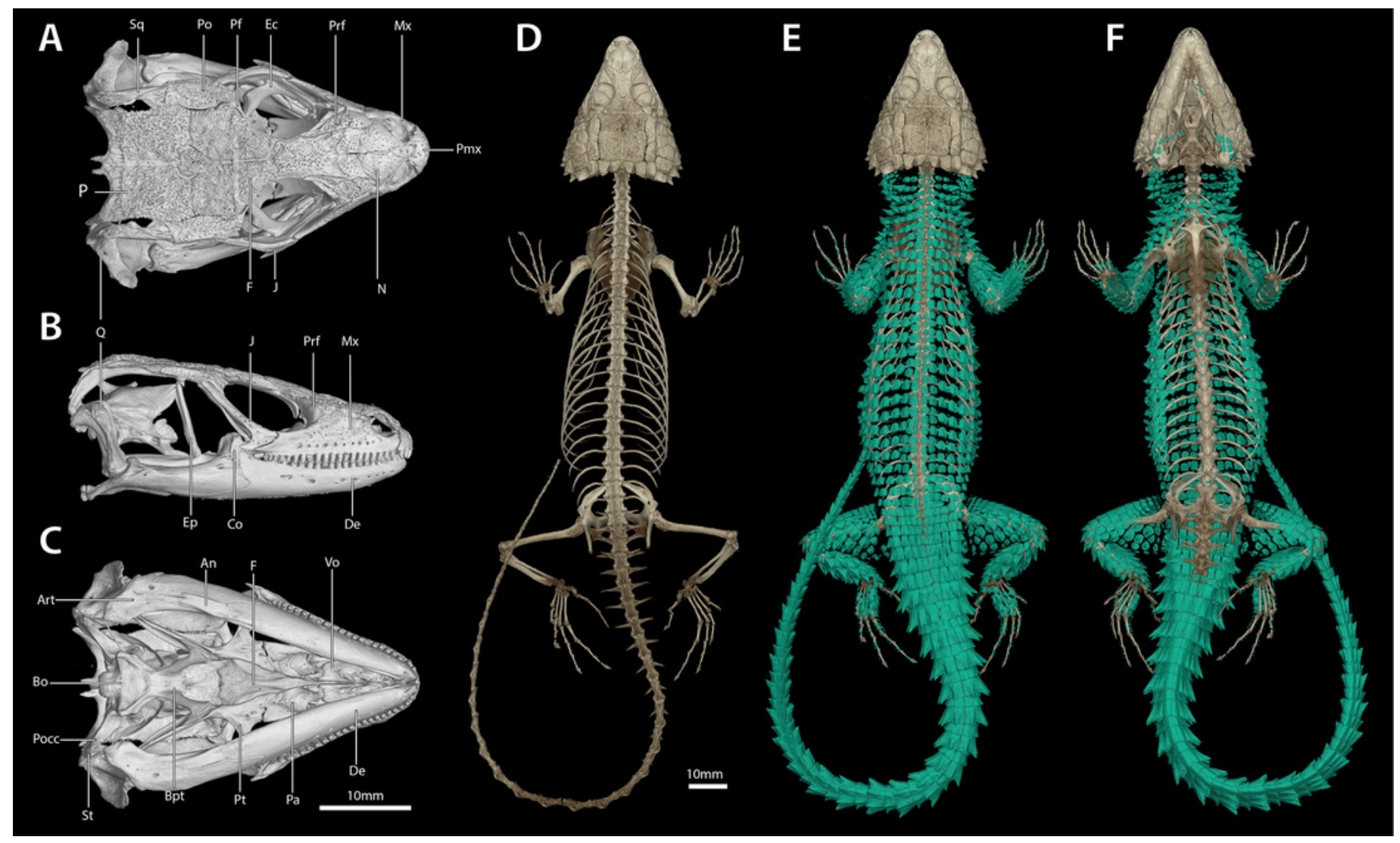


Figure 8

(A) Habitat at Malolotja National Park, Eswatini, vicinity of type locality of Smaug swazicus sp. nov. (B) Dorsal colouration of live paratype of S. swazicus (NMB R9194). (C) Ventral colouration of the same specimen.

(Photo credits: E.L. Stanley)

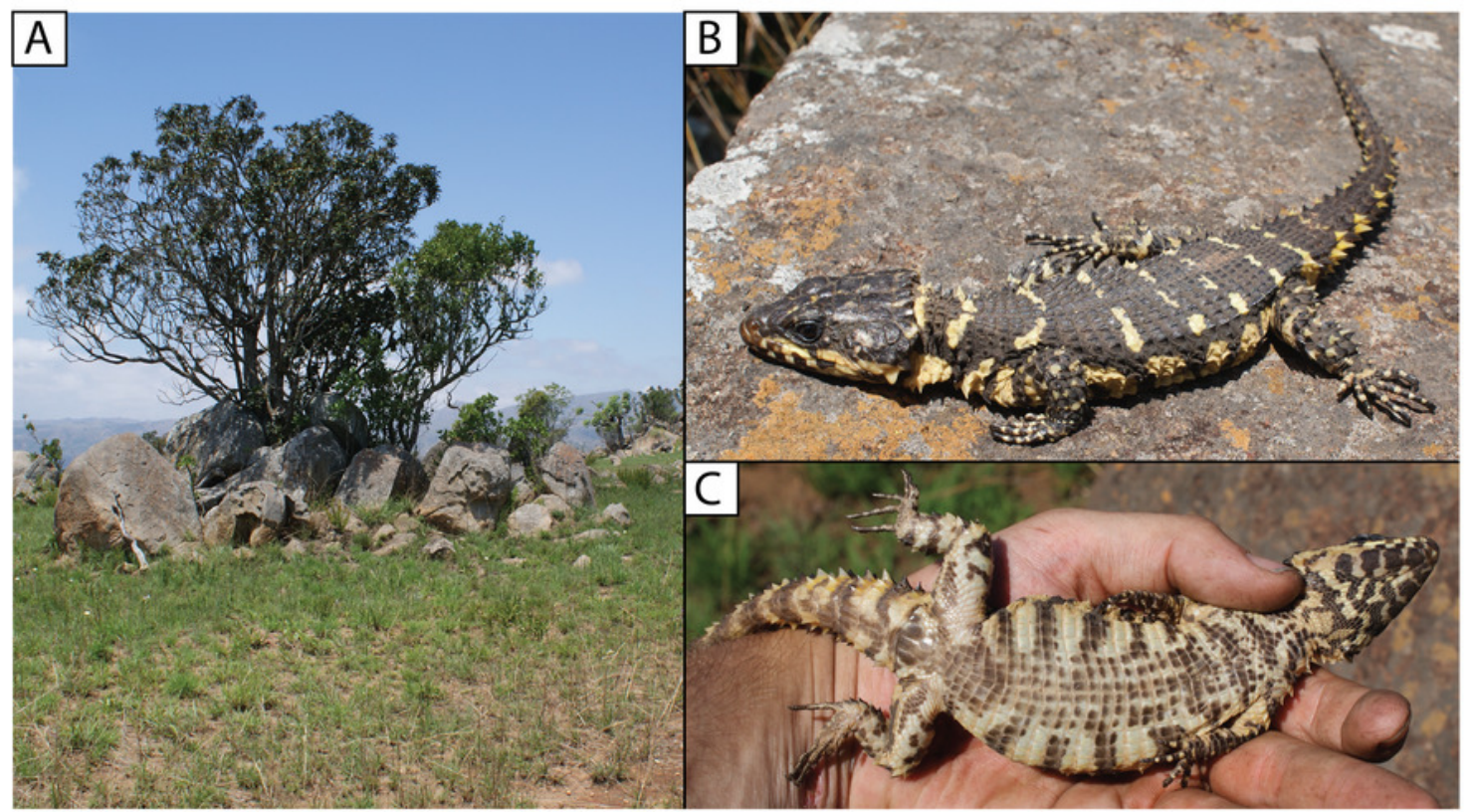


Figure 9

Map showing recorded localities of Smaug barbertonensis (red) S. swazicus sp. nov. (green) and S. warreni (blue).

Filled circles denote museum records, while open circles show geo-referenced photo vouchers from University of Cape Town's Animal Demography Unit Virtual Museum. The type locality for each species is represented by a star. (Image produced by: E.L. Stanley) 


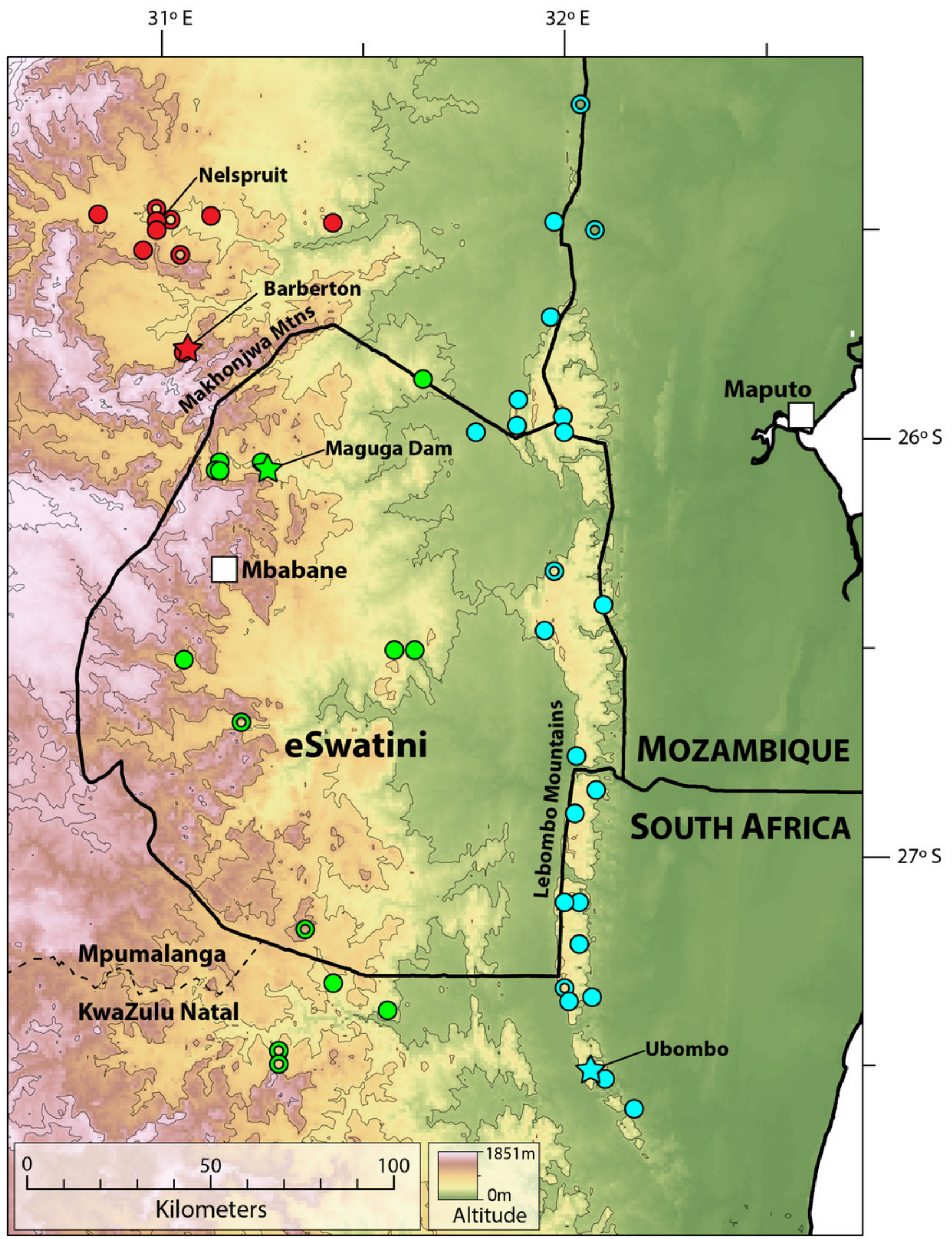


Figure 10

Smaug barbertonensis. (A) Dorsal, (B) ventral and (C) lateral views of the head of NMB R9191 (topotype). (Drawing credit: E.L. Stanley)
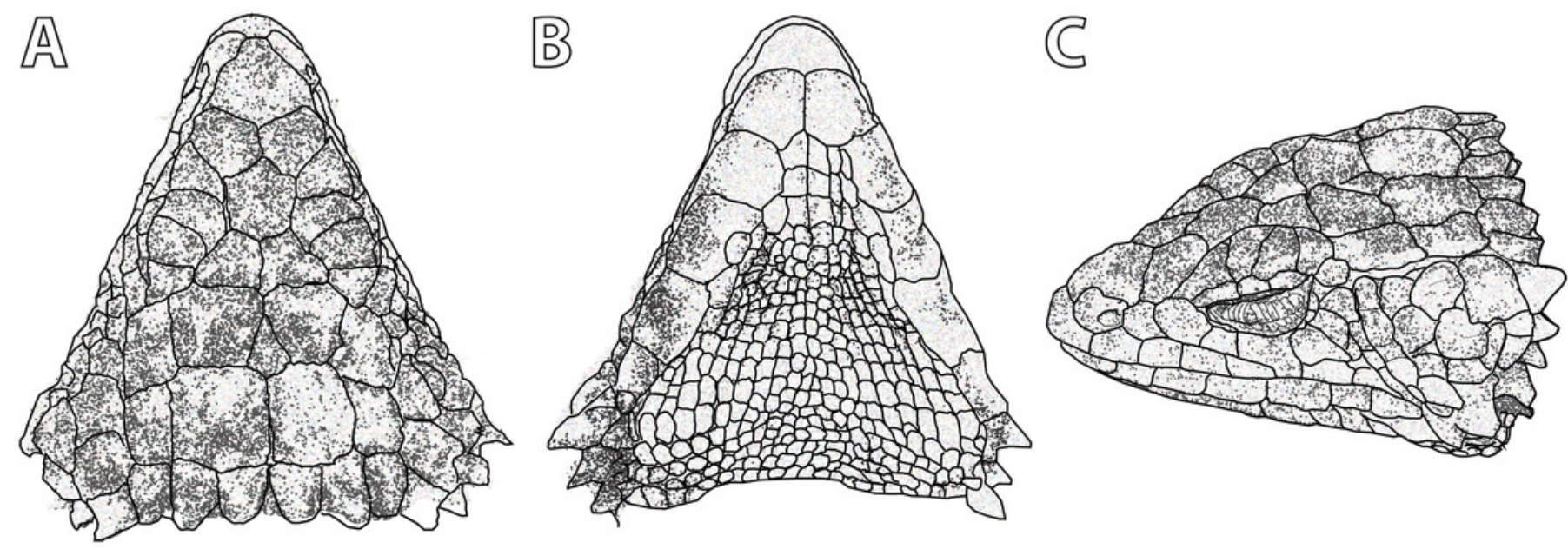


\section{Figure 11}

Cranial (A-C), postcranial (D), and dermal (E-F) osteology of Smaug barbertonensis (NMB R9196, topotype).

Body ostoderms are highlighted in blue-green. Abbreviations: An, angular; Art, articular; Bo, basioccipital; Bpt, basipterygoid; Co, coranoid; De, dentary; Ec, ectopterygoid; Ep, epipterygoid; F, frontal; J, jugal; Mx, maxilla; N, nasal; P, parietal; Pa, palatine; Pf, postfrontal; Pmx, premaxilla; Po, postorbital; Pocc, paraoccipital; Prf, prefrontal; Pt, pterygoid; Q, quadrate; Sq, squamosal; St, supratemporal; Vo, vomer. (Images produced by: E.L. Stanley)

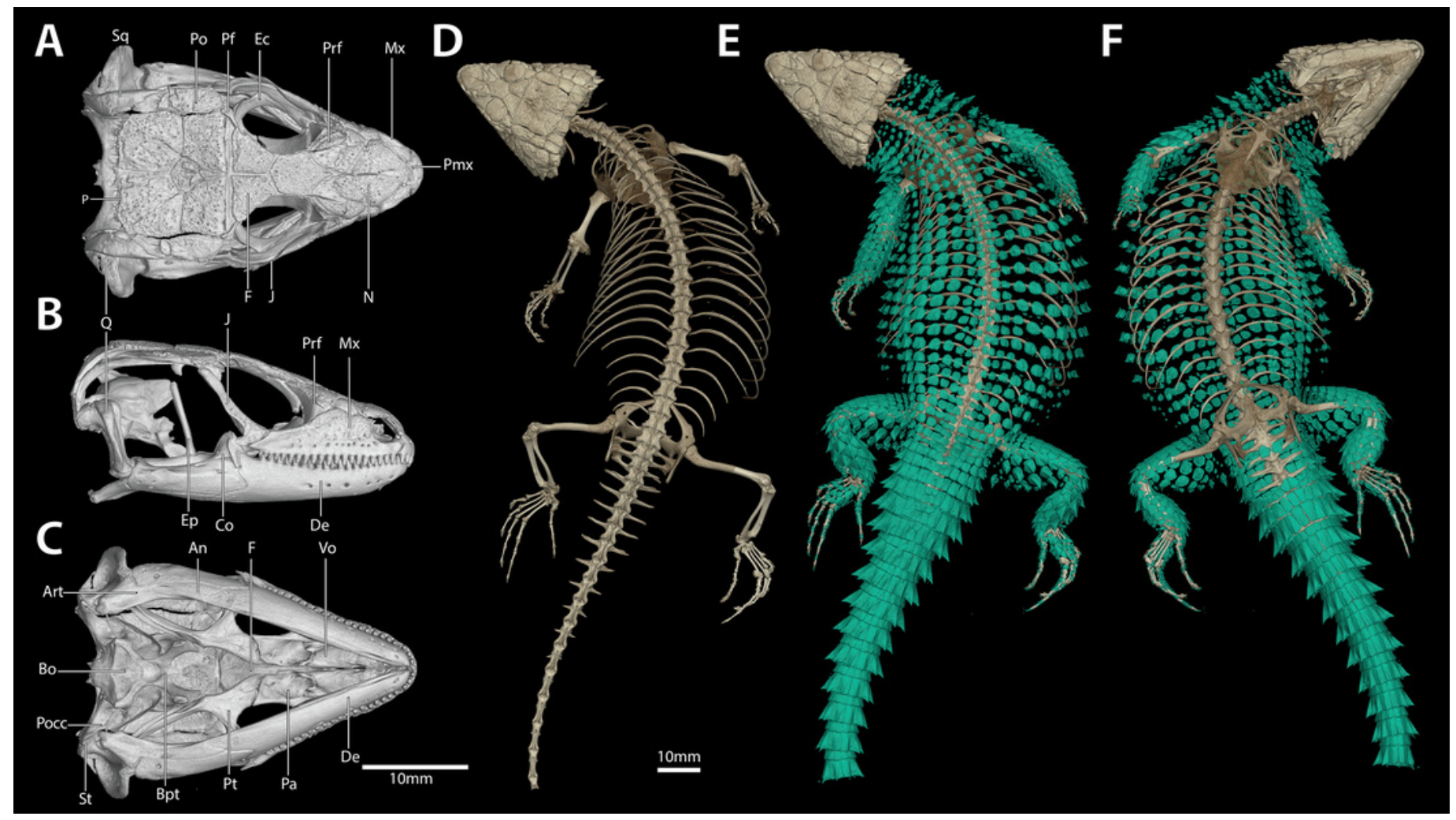




\section{Figure 12}

(A) Smaug barbertonensis habitat, Nelspruit (Extension 5), Mpumalanga Province, South Africa. (B) Dorsal colouration of $S$. barbertonensis from the latter locality. (C) Ventral colouration of $S$. barbertonensis

(same specimen). (Photo credits: Theo Busschau)

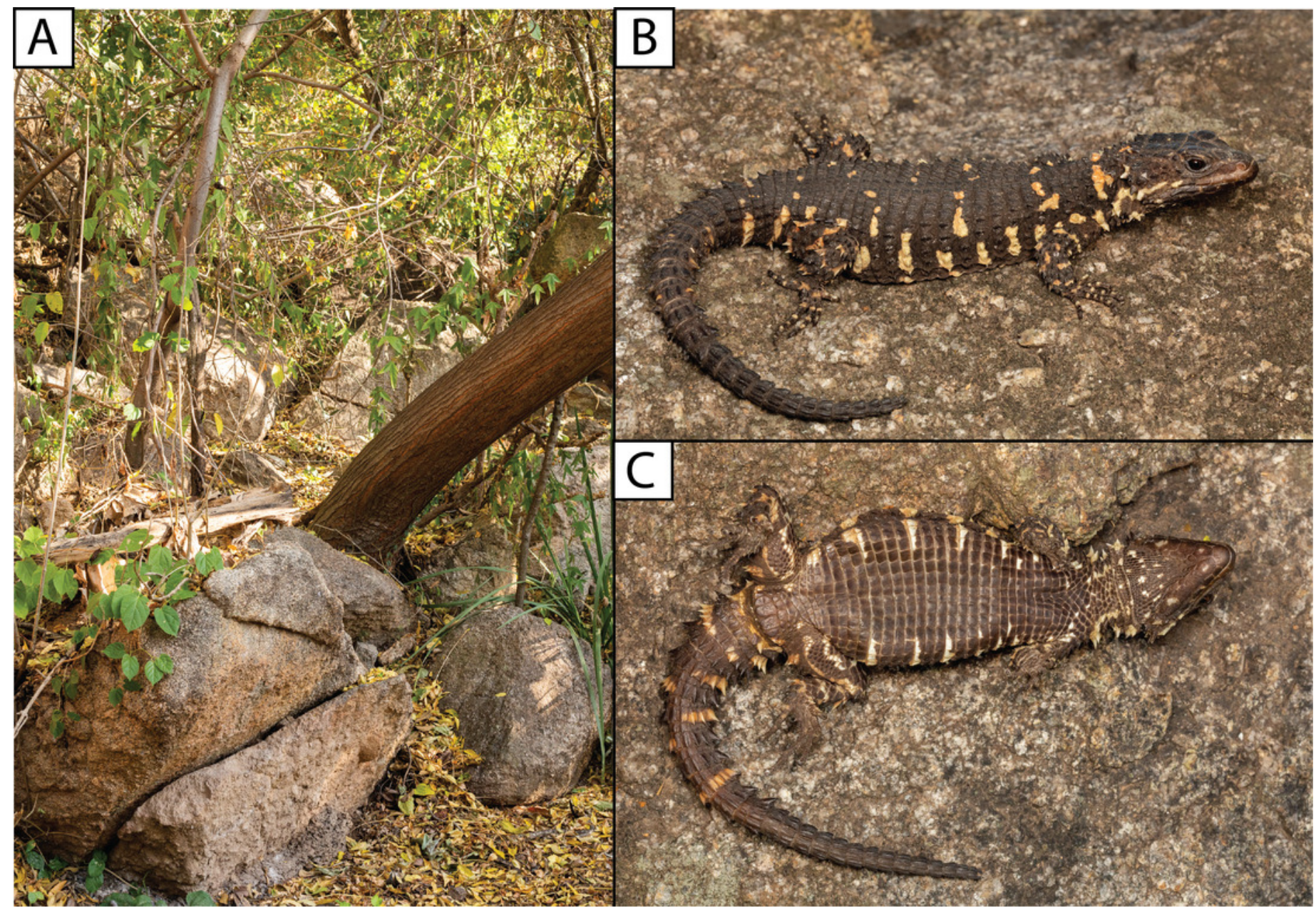


Figure 13

Smaug warreni. (A) Dorsal, (B) ventral and (C) lateral views of the head of TM 50130 (Lomahasha, Eswatini). (Drawing credit: E.L. Stanley)
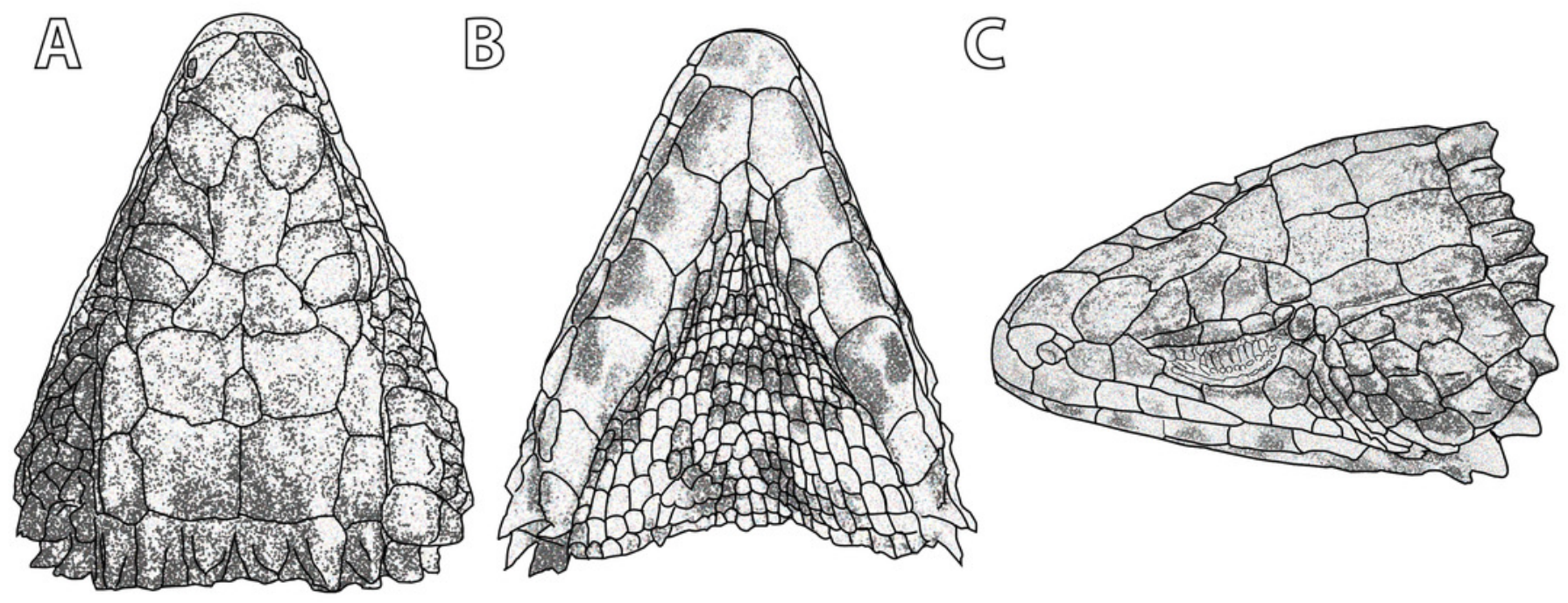


\section{Figure 14}

Cranial (A-C), postcranial (D), and dermal (E-F) osteology of Smaug warreni (NMB R9292).

Body ostoderms are highlighted in blue-green. Abbreviations: An, angular; Art, articular; Bo, basioccipital; Bpt, basipterygoid; Co, coranoid; De, dentary; Ec, ectopterygoid; Ep, epipterygoid; F, frontal; J, jugal; Mx, maxilla; N, nasal; P, parietal; Pa, palatine; Pf, postfrontal; Pmx, premaxilla; Po, postorbital; Pocc, paraoccipital; Prf, prefrontal; Pt, pterygoid; Q, quadrate; Sq, squamosal; St, supratemporal; Vo, vomer. (Images produced by: E.L. Stanley)

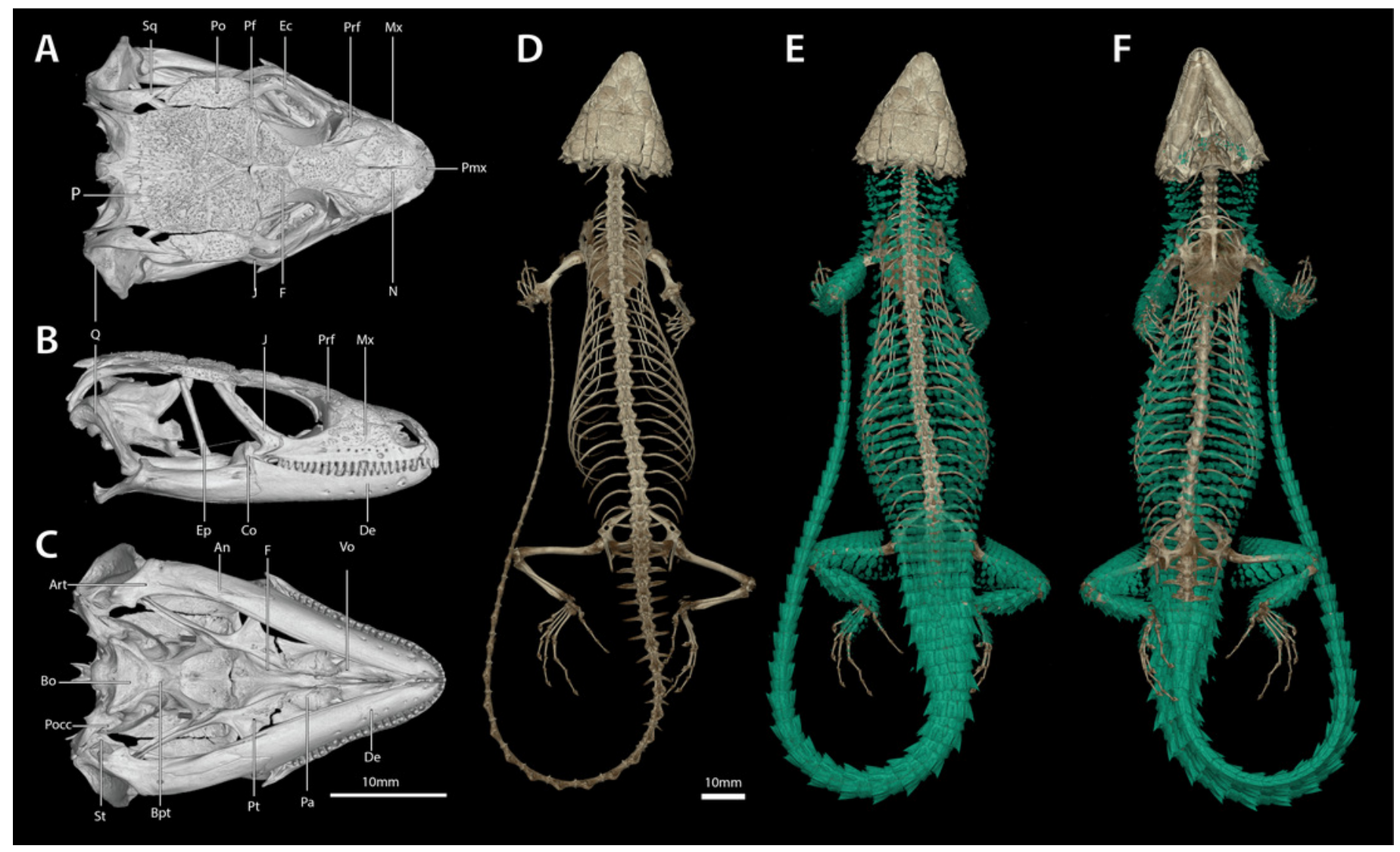




\section{Figure 15}

(A) Smaug warreni habitat, northern Lebombo mountains, Mpumalanga Province, South Africa. (B) Dorsal colouration of S. warreni. (Photo credit: E.L. Stanley).

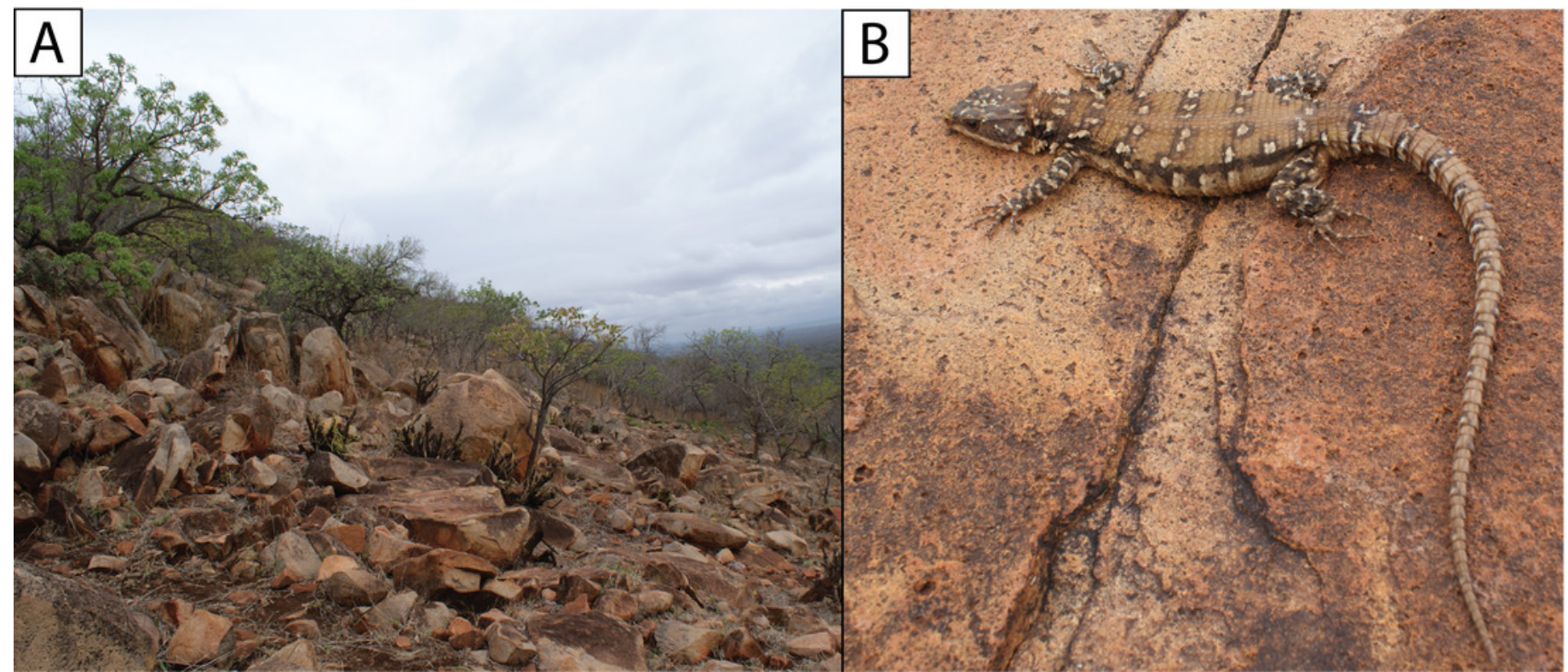

